\title{
Copper (I) SNS Pincer Complexes: Impact of Ligand Design and Solvent Coordination on Conformer Interconversion from Spectroscopic and Computational Studies
}

\author{
Matthew A. Lynn \\ John R. Miecznikowski

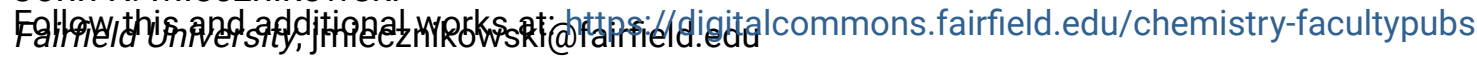 \\ (C) 2019 Elsevier B.V. All rights reserved. \\ thisy work Is linski
}

Aigeppleet Kaur

The author post-print has been archived here with permission from the copyright holder. Brandon Q. Mercado

\section{Peer Reviewed}

See next page for additional authors

\section{Repository Citation}

Lynn, Matthew A.; Miecznikowski, John R.; Jasinski, Jerry P.; Kaur, Manpreet; Mercado, Brandon Q.; Reinheimer, Eric; Almanza, Emilse; Kharbouch, Rami M.; Smith, Michael R.; Zygmont, Samantha E.; Flaherty, Nicole F.; and Smith, Amber C., "Copper (I) SNS Pincer Complexes: Impact of Ligand Design and Solvent Coordination on Conformer Interconversion from Spectroscopic and Computational Studies" (2019). Chemistry \& Biochemistry Faculty Publications. 45. https://digitalcommons.fairfield.edu/chemistry-facultypubs/45

\section{Published Citation}

Lynn, M.A., Miecznikowski, J.R., Jasinski, J.P., Kaur, M., Mercado, B.Q., Reinheimer, E., Almanza, E., Kharbouch, R.M., Smith, M.R., Zygmont, S.E. and Flaherty, N.F. (2019). Copper (I) SNS Pincer Complexes: Impact of Ligand Design and Solvent Coordination on Conformer Interconversion from Spectroscopic and Computational Studies. Inorganica Chimica Acta, 118996. https://doi.org/10.1016/j.ica.2019.118996

This item has been accepted for inclusion in DigitalCommons@Fairfield by an authorized administrator of DigitalCommons@Fairfield. It is brought to you by DigitalCommons@Fairfield with permission from the rightsholder(s) and is protected by copyright and/or related rights. You are free to use this item in any way that is permitted by the copyright and related rights legislation that applies to your use. For other uses, you need to obtain permission from the rights-holder(s) directly, unless additional rights are indicated by a Creative Commons license in the record and/or on the work itself. For more information, please contact digitalcommons@fairfield.edu. 


\section{Authors}

Matthew A. Lynn, John R. Miecznikowski, Jerry P. Jasinski, Manpreet Kaur, Brandon Q. Mercado, Eric Reinheimer, Emilse Almanza, Rami M. Kharbouch, Michael R. Smith, Samantha E. Zygmont, Nicole F. Flaherty, and Amber C. Smith 


\section{Copper(I) SNS Pincer Complexes: Impact of Ligand Design and Solvent Coordination on Conformer Interconversion from Spectroscopic and Computational Studies}

Matthew A. Lynn*[a], John R. Miecznikowski*[b], Jerry P. Jasinski[c], Manpreet Kaur[c], Brandon Q. Mercado[d], Eric Reinheimer[e], Emilse Almanza ${ }^{[b]}$, Rami M. Kharbouch ${ }^{[b]}$, Michael R. Smith ${ }^{[b]}$, Samantha E. Zygmont ${ }^{[b]}$, Nicole F. Flaherty ${ }^{[b]}$, and Amber C. Smith $[b]$

a Department of Science and Mathematics, National Technical Institute for the Deaf, Rochester Institute of Technology, 52 Lomb Memorial Drive, Rochester, NY 14623, U.S.A.

b Department of Chemistry and Biochemistry, Fairfield University, 1073 North Benson Road, Fairfield CT 06824, U.S.A.

c Department of Chemistry, Keene State College, 229 Main Street, Keene, NH 03435, U.S.A.

d Department of Chemistry, Yale University, 225 Prospect Street, New Haven, CT 06520-8107 U.S.A.

e Rigaku Corporation Americas, 9009 New Trails Drive, The Woodlands, TX 773815209. U.S.A.

Corresponding Author $=*$ Matthew A. Lynn, Department of Science and Mathematics, National Technical Institute for the Deaf, Rochester Institute of Technology, 52 Lomb Memorial Drive, Rochester, NY 14623, U.S.A.

E-mail:malntm@rit.edu

Corresponding Author $={ }^{*}$ John R. Miecznikowski, Department of Chemistry and Biochemistry, Fairfield University, 1073 North Benson Road, Fairfield CT 06824, U.S.A. E-mail: jmiecznikowski@fairfield.edu 


\begin{abstract}
The syntheses and detailed characterizations (X-ray crystallography, NMR spectroscopy, cyclic voltammetry, infrared spectroscopy, electrospray mass spectrometry, and elemental analyses) of two new $\mathrm{Cu}(\mathrm{I})$ pincer complexes are reported. The pincer ligand coordinates through one nitrogen and two sulfur donor atoms and is based on bis-imidazole or bis-triazole precursors. These tridentate SNS ligands incorporate pyridine and thione-substituted imidazole or triazole functionalities with connecting methylene units that provide flexibility to the ligand backbone and enable high bite-angle binding. Variable temperature ${ }^{1} \mathrm{H}$ NMR analysis of these complexes and of a similar zinc(II) SNS system shows that all are fluxional in solution and permits the determination of $\Delta \mathrm{G}_{\exp } p^{\ddagger}$ and $\Delta \mathrm{S}_{\exp } p^{\ddagger}$. DFT calculations are used to model the fluxionality of these complexes and indicate that a coordinating solvent molecule can promote hemilability of the SNS ligand by lowering the energy barrier involved in the partial rotation of the methylene units.
\end{abstract}

Keywords: tridentate $\mathrm{Cu}(\mathrm{I})$ SNS pincer complexes; solvent-induced hemilability; density functional calculations; transition state analysis; variable temperature NMR spectroscopy 


\section{Introduction}

Pincers, three-coordinate ligands that generally bind to metal centers in a meridional fashion, have been the focus of considerable study over recent decades.[1] With three points of attachment to a central metal atom, metal-bound pincers possess a particular robustness that has permitted their use across a broad range of reaction conditions. Of particular interest has been their applicability as a catalyst for the generation of substituted alkenes via, for example, the Heck reaction as well as hydrogenations and dehydrogenations.[2, 3, and references therein] A great deal of tunability of these complexes has been explored given the wide range of metal centers that are available and ligand backbones that can be designed. Pincers can be constructed using a variety of organic precursors that permit these ligands to bind to the metal center via a range of donor atoms (usually $\mathrm{C}, \mathrm{O}, \mathrm{N}, \mathrm{P}$, or $\mathrm{S}$ ) and to be electronically and structurally modified through the inclusion of aromatic substituents and bulky and/or chiral groups.

The fine-tuning that can be accomplished through the use of the various structural modifications within the ligand can, in general, be reasonably assumed to affect the reactivity of pincer-bound complexes. We focus here on two specific properties, the fluxionality and hemilability of the pincer ligand.[4] The fluxional behavior of a metal-bound system can be adjusted through appropriate design of the pincer. Inclusion of alkyl linker chains that bridge the donor atom-containing functionalities in the pincer has been shown to increase this internal fluxionality, the thermodynamics of which can be understood via temperature-dependent NMR.[512] Additionally, it is possible for at least one of the three metal-pincer bonds to be 
weakened significantly or broken as a result of displacement by some external donor. Such a characteristic has been termed hemilability. [13] For pincers, the detachment of just one of the three coordinating groups generally does not lead to the decomposition of the entire complex given that the displaced donor atom, still connected to the system via the pincer backbone, remains nearby. Such hemilability has been shown to be critical in determining the catalytic efficiency of a $\mathrm{Ni}(\mathrm{II})$-bound NNN pincer complex used to catalyze a Sonogashira coupling.[14]

Of particular note is a study by Crabtree and co-workers who have described the impact not only of intraligand design modifications but also of counteranions on the fluxionality of a pincer-bound system on the NMR time scale. $[12,15]$ These Pd(II) CCC $\quad\left(\mathrm{CCC}=\kappa^{3}-\mathrm{C}, \mathrm{C}^{\prime}, \mathrm{C}^{\prime \prime}\right)(2,6-$ bis $\{[\mathrm{N}$-methyl-N'-methylene $]$ imidazol-2ylidene $\}$ phenyl) $)$ and $\mathrm{Pd}(\mathrm{II}) \quad \mathrm{CNC}$ (CNC $=\left(\kappa^{3}-\mathrm{C}, \mathrm{C}^{\prime}, \mathrm{N}\right)\left(2,6-\mathrm{bis}\left\{\left[\mathrm{N}-\mathrm{methyl}-\mathrm{N}^{\prime}-\right.\right.\right.$ methylene]imidazol-2-ylidene\}pyridine)) pincer complexes are of the general formula $\left[(\mathrm{CCC}) \mathrm{Pd}\left(\mathrm{X}_{\mathrm{IS}}\right)\right]$ or $\left[(\mathrm{CNC}) \mathrm{Pd}\left(\mathrm{X}_{\mathrm{IS}}\right)\right]\left[\mathrm{X}_{\mathrm{OS}}\right]$ where $\mathrm{X}_{\mathrm{IS}}$ and $\mathrm{X}_{\text {os }}$ refer to inner sphere and outer sphere anions, respectively. (eq. 1 and eq. 2) The interconversion of the atropisomeric conformations was evidenced by the coalescence of the $\mathrm{Ha}_{\mathrm{a}}$ and $\mathrm{Hb}$ methylene proton resonances on the NMR timeframe at relatively high temperatures and is believed to be caused by the stepwise partial side-to-side rotation of the individual methylene groups across the plane of the pincer ligand's pyridinyl group. If, for example, such pincer complexes are to be employed as asymmetric catalysts, it is likely necessary to prevent this kind of interconversion.[15] 

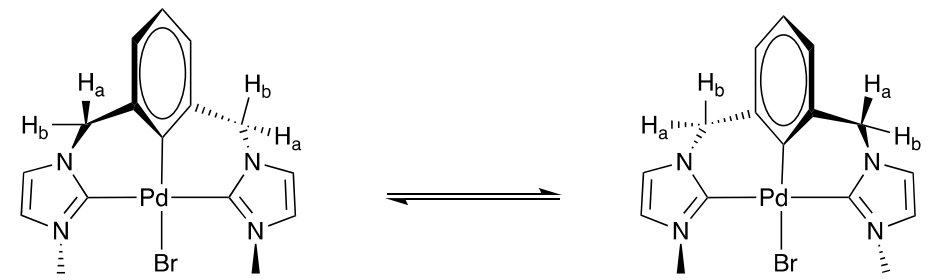

(eq. 1)
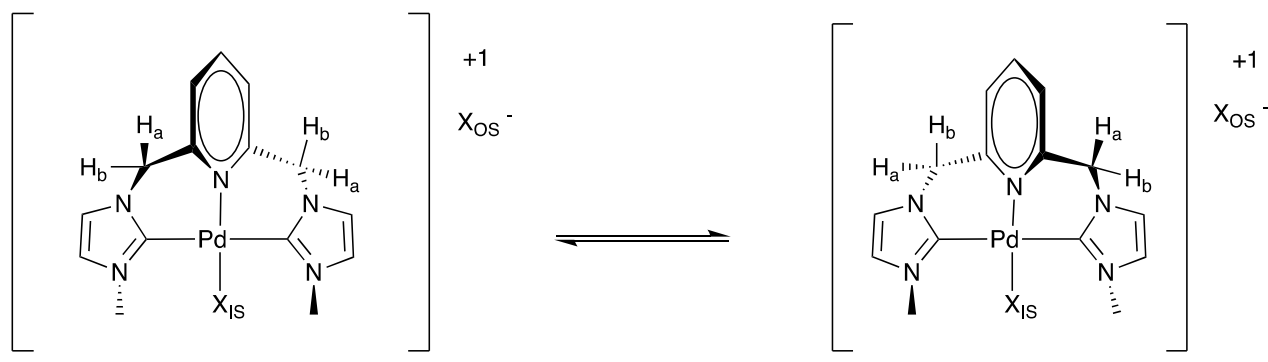

(eq. 2)

To understand this structural behavior, Crabtree and co-workers reported that different mechanisms may be involved in the interconversion of the Pd(II) pincer complexes and that in this specific case, the solvent did not appear to be a contributing factor. When there is no outer sphere ion present (eq. 1) or there is a weakly nucleophilic counterion $\left(\mathrm{Xos}_{\mathrm{oS}}=\mathrm{OTs}^{-}\right.$) (eq. 2), the interconversion happens without any change in coordination number of the metal center. When there is a nucleophilic outer sphere counteranion $\left(\mathrm{X}_{\mathrm{OS}}=\mathrm{Cl}^{-}, \mathrm{Br}^{-}, \mathrm{I}^{-}\right)$, this ion can displace the pyridine moiety of the CNC pincer complex to give a lower-energy pathway for the interconversion of the Pd(II) complexes. In all cases for the Pd(II) systems, the presence of a [MXIS]-Xos tight ion pair and not the availability of a nucleophilic solvent molecule were described as governing the activation energies for the fluxional process.

As a result of our own interest in designing pincer-based transition metal compounds based on the various principles and factors described above, we have 
investigated the use of neutral SNS-donor pincers with various late transition metals. Our current study focuses on the $\mathrm{Cu}(\mathrm{I})$-bound systems $\mathbf{1}$ and $\mathbf{2}$ shown in Figure 1. These complexes possess a three-coordinate $\mathrm{Cu}(\mathrm{I})$ center with metal-ligand bonds solely between the copper atom and the SNS donor atoms. The counterion is a noncoordinating tetrafluroborate anion.

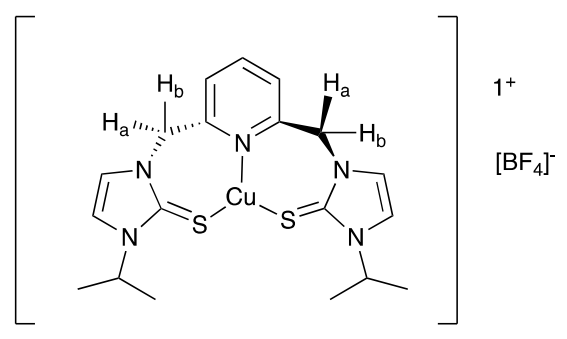

(1)

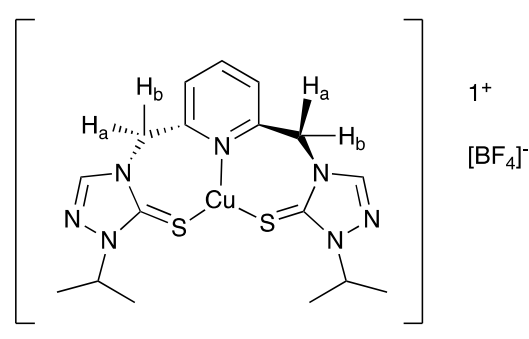

(2)

Figure 1. New copper(I) SNS pincer complexes prepared and studied in this report.

Prior to the preparation of $\mathbf{1}$ and $\mathbf{2}$, we designed a series of zinc(II) complexes with the goal of developing a model for the catalytically active site in liver alcohol dehydrogenase $[16,17]$ where there are two sulfur-donor cysteines and a nitrogendonor histidine.[18] The uniting theme across our current and previous work is that these systems feature a pincer ligand that coordinates to the metal center via sulfur and nitrogen donor atoms. The structural and electronic properties of our tridentate ligand can be easily modified through selection of the pyridine and azole starting materials. For instance, the relative flexibility of the ligand precursor can be adjusted through the use of a haloalkyl-substituted pyridine. Specifically, employing 2,6bis(bromomethyl)pyridine allows for the introduction of a methylene linker to connect the pyridine to the azole ring, thereby introducing a greater degree of 
flexibility (Figure 2, 4a-c) into the pincer than if 2,6-dibromopyridine were used (Figure 2, 3a-c). Using a triazole allows for further adjustment of the pincer's structural and electronic properties (Figure 2, 5a-c).
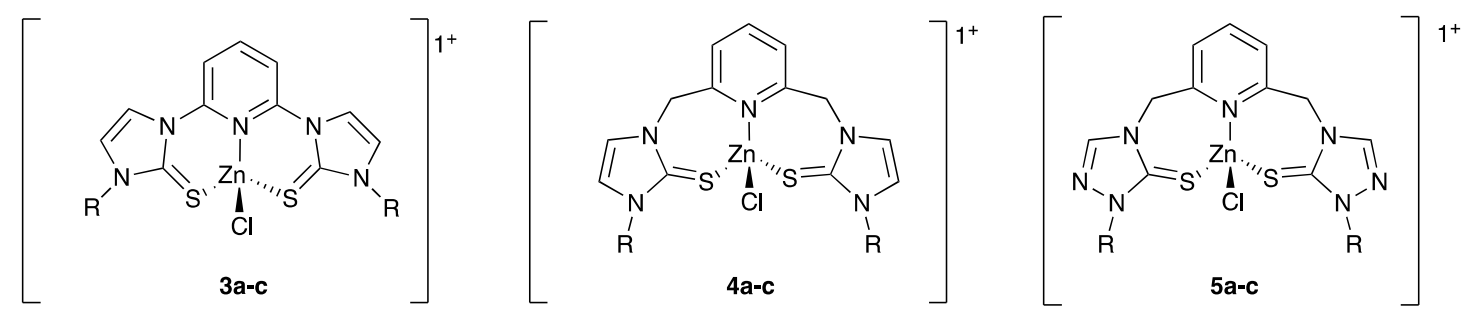

$\mathrm{R}=\mathrm{a}=\mathrm{iPr}, \mathrm{b}=$ neopentyl; $\mathrm{c}=\mathrm{n}$-butyl

Figure 2. Zinc(II) SNS pincer complexes previously synthesized and characterized.

Following our work on these Zn(II) systems, we endeavored to extend the coordination chemistry and reactivity of our SNS pincer ligands by binding them to copper centers. The result was our synthesis and characterization of a series of fivecoordinate copper(II) complexes (Figure 3, 6a-c) and three-coordinate copper(I) complexes (Figure 3, 7a-c and 8a-c).[19,20] As was the case for the zinc compounds, the structures of the copper complexes were tuned through the use of methylene linkers connecting imidazole or triazole units to the pyridine rings.

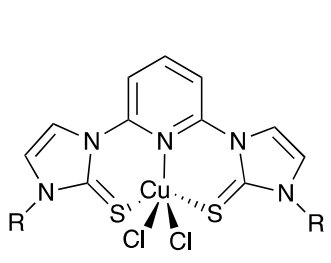

6a-c

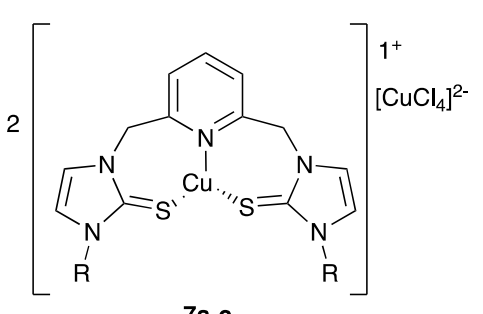

7a-c

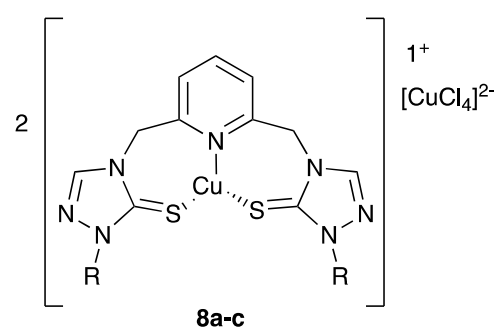

$\mathrm{R}=\mathrm{a}=\mathrm{iPr}, \mathrm{b}=$ neopentyl; $\mathrm{c}=\mathrm{n}$-butyl

Figure 3. Copper(I)- and copper(II)-coordinated SNS pincer complexes previously synthesized and characterized. 
Based on the solid-state structures we have obtained for the complexes given in Figure 3, we know that there are copper ions in both the cation and the counteranion for complexes 7a-c and 8a-c. Replacing the $\left[\mathrm{CuCl}_{4}\right]^{2-}$ anion with a non-transitionmetal-containing and non-coordinating anion has led to the complexes that we report in our current study.

We describe here the syntheses, single crystal structures, NMR characterizations, electrochemical characterizations, electrospray mass spectrometry, elemental analyses, and infrared spectroscopy analyses of $\mathbf{1}$ and $\mathbf{2}$. In order to investigate and better understand the fluxional behavior of these complexes and the mechanism for interconversion, we performed variable temperature NMR experiments and DFT calculations on the complexes, which are reported in detail. This work extends our understanding of the fluxionality of $\mathrm{Cu}(\mathrm{I})$ - and $\mathrm{Zn}(\mathrm{II})-\mathrm{SNS}$ pincer complexes and provides further insight into the work done previously to explore the similar behavior of Pd(II)-CNC systems.

\section{Experimental}

\section{General Procedures}

Reagents and solvents were commercially available and were purchased from Acros Organics, and Fisher Scientific. All chemicals were used as received.

Isopropylimidazole and isopropyltriazole were prepared according to literature procedures.[21,22] 2,6-Bis(N-isopropyl-N'-methyleneimidazole)pyridine bromide, 2,6-bis(N-isopropyl-N'-methylenetriazole)pyridine bromide, 2,6-bis(Nisopropyl-N'-methyleneimidazole-2-thione)pyridine $\left(\mathrm{C}_{19} \mathrm{H}_{25} \mathrm{~N}_{5} \mathrm{~S}_{2}\right)$, and 2,6-bis(N- 
isopropyl-N'-methylenetriazole-2-thione)pyridine $\left(\mathrm{C}_{17} \mathrm{H}_{23} \mathrm{~N}_{7} \mathrm{~S}_{2}\right)$ were prepared following literature procedures.[16]

NMR spectra were recorded at $25^{\circ} \mathrm{C}$ (unless otherwise noted) on a Bruker spectrometer at $300 \mathrm{MHz}$ or $400 \mathrm{MHz}\left({ }^{1} \mathrm{H}\right.$ NMR) or a $400 \mathrm{MHz}$ JEOL spectrometer and $75 \mathrm{MHz}$ Bruker ( ${ }^{13} \mathrm{C}$ NMR) spectrometer and referenced to DMSO ( $\delta$ in ppm, $J$ in $\mathrm{Hz}$ ). All temperatures were corrected.[23] The ${ }^{1} \mathrm{H},{ }^{13} \mathrm{C}\left\{{ }^{1} \mathrm{H}\right\}$, and HSQC NMR spectra are included in the supporting information section.

Elemental analyses were performed by Robertson Microlit Laboratories (Ledgewood, NJ, USA). Residual solvent molecules were identified by ${ }^{1} \mathrm{H}$ NMR. Electrospray mass spectra were collected using a direct flow injection (injection volume $=5 \mathrm{uL}$ ) on an Agilent QTOF instrument in positive and negative ion mode. The optimized conditions were capillary $=3000 \mathrm{kV}$, cone $=10 \mathrm{~V}$, source temperature $=120^{\circ} \mathrm{C}$. UV-visible spectra were collected on a Cary $100 \mathrm{UV}$-Visible Spectrometer. The IR spectra were collected using a Bruker-Tensor 27 FT-IR with an ATR accessory. The ESI-MS, UV-VIS, and ATR-IR spectra are included in the supporting information section.

Cyclic voltammetry experiments were performed using a Gamry Electroanalytical System with a silver wire reference electrode, a glassy carbon working electrode, and a platinum counter electrode. The supporting electrolyte for the cyclic voltammetry experiments was tetra-N-butylammonium tetrafluoroborate $(0.20 \mathrm{M})$. The solvent for the cyclic voltammetry experiments was dimethyl sulfoxide. The ferrocenium/ferrocene couple was used as an internal reference; reduction potential values were corrected by assigning the ferrocenium/ferrocene couple to 
$0.40 \mathrm{~V}$ versus SCE. The concentration of the copper complex for the cyclic voltammetry was $2.08 \mathrm{mM}$ for $\mathbf{1}$ and $2.04 \mathrm{mM}$ for $\mathbf{2}$. The solution was degassed with nitrogen before collecting cyclic voltammetry spectra. The scan rates were $100 \mathrm{mV} / \mathrm{s}$. The cyclic voltammograms are included in the supporting information section.

Gaussian 09 was used to perform geometry optimizations on all structures presented in this report.[24] The B3LYP hybrid functional and basis sets (6$311 \mathrm{G}(\mathrm{d}, \mathrm{p})$ for $\mathrm{Cu}$ and $\mathrm{Zn}$ and $6-31 \mathrm{G}(\mathrm{d})$ for $\mathrm{H}, \mathrm{C}, \mathrm{N}, \mathrm{S}$, and $\mathrm{Cl})$ as provided with the software were used to perform the DFT calculations. In all cases, a methyl group was used to represent the pendant group on the pincer ligand. Symmetry was imposed on structures as indicated in the discussion. Except in a few cases as described below, all calculations were performed on gas-phase structures without the use of any kind of continuum solvent model.

Vibrational analyses were performed on the optimized structures to determine whether they represented minima or transition states. As we have observed previously,[25] no or small imaginary frequencies (none more negative than $-35 \mathrm{~cm}^{-1}$ ) were obtained for structures corresponding to ground-state minima. In the frequency analysis for structures representing transition state structures, a vibration at a more negative wavenumber (at or below $-135 \mathrm{~cm}^{-1}$ ) was obtained for each structure. The starting guesses for the transition state structures were constructed by imposing the fewest number of frozen structural parameters necessary to force the coplanarity of the methylene carbon atom and adjacent atoms in the pyridinyl and azolyl functionalities. These structures were then optimized with the imposed constraints. The Cartesian coordinates of all optimized structures 
presented as well as the specific parameters used to freeze parts of the transition state molecular structures are provided in the supplementary information.

\section{Syntheses}

Synthesis of Bis-[( $\left.\mathrm{K}^{3}-S, S, N\right)(2,6$-bis $)\left\{\left[N\right.\right.$-isopropyl- $N^{\prime}$-methylene $]$ imidazole-1-ylidene-2thione\} pyridine copper(I) tetrafluoroborate (1)

In a $100 \mathrm{~mL}$ round bottom flask, $0.217 \mathrm{~g}\left(5.60 \times 10^{-4} \mathrm{~mol}\right)$ of $\mathrm{C}_{19} \mathrm{H}_{25} \mathrm{~N}_{5} \mathrm{~S}_{2}$ was combined with $0.136 \mathrm{~g}\left(5.60 \times 10^{-4} \mathrm{~mol}\right)$ of copper(II) tetrafluoroborate $\left(\mathrm{Cu}\left(\mathrm{BF}_{4}\right)_{2}\right)$ and dissolved in 10. $\mathrm{mL}$ of acetonitrile. The solution was refluxed for 20 hours. During the reaction time, the solution changed color from orange to dark brown. The following day, the solvent was removed under reduced pressure. Yield: $0.282 \mathrm{~g}(93.6 \%)$. Olive green crystals for X-ray diffraction were grown by a slow vapor diffusion of diethyl ether into an acetonitrile solution containing the copper complex. The mass of the titled product after recrystallization was $0.200 \mathrm{~g}(66.6 \%)$.

Anal. Calc. for $\mathrm{C}_{19} \mathrm{H}_{25} \mathrm{CuN}_{5} \mathrm{~S}_{2} \mathrm{BF}_{4}$ (537.91): C, 42.42; H, 4.68; N, 13.02. Found: C, 42.25; H, 4.43; N, 12.95.

High-resolution electrospray mass spectrometry (positive ion mode) $\mathrm{m} / \mathrm{z}=$ 450.09455 (molecular ion).

High-resolution electrospray mass spectrometry (negative ion mode) $\mathrm{m} / \mathrm{z}=$ 87.01923 (molecular ion).

${ }^{1} \mathrm{H}$ NMR (DMSO-d6, $\left.300 \mathrm{MHz}\right) \delta 8.24(\mathrm{~m}, 1 \mathrm{H}$, pyridine $\mathrm{CH}) ; 8.00(\mathrm{~m}, 2 \mathrm{H}$, pyridine $\mathrm{CH})$; $7.66(\mathrm{~m}, 2 \mathrm{H}(\mathrm{J}=2 \mathrm{~Hz})$, imidazole $\mathrm{CH}) ; 7.55(\mathrm{~m}, 2 \mathrm{H}(\mathrm{J}=2 \mathrm{~Hz})$, imidazole $\mathrm{CH}) ; 5.50$ 
(broad s, 4H, CH2); 4.83 (septet, 2H, ( $\left.\left.{ }^{3} \mathrm{~J}=6.9 \mathrm{~Hz}\right), i \operatorname{Pr}-\mathrm{H}\right) ; 1.41$ (d, ( $\left.{ }^{3} \mathrm{~J}=6.6 \mathrm{~Hz}\right), 12 \mathrm{H}, i \mathrm{Pr}$ $\left.\mathrm{CH}_{3}\right)$.

${ }^{13} \mathrm{C}\left\{{ }^{1} \mathrm{H}\right\}$ NMR (DMSO-d6, $75 \mathrm{MHz}$ ), $\delta$ 154.75; 153.37; 141.55 (pyridine CH); 126.06 (pyridine $\mathrm{CH}$ ); 119.98 (imidazole $\mathrm{CH}$ ); 116.51 (imidazole $\mathrm{CH}$ ); $51.96\left(\mathrm{CH}_{2}\right) ; 50.06$ $\left(\mathrm{H}_{3} \mathrm{CCHCH}_{3}\right) ; 21.30\left(i \mathrm{Pr} \mathrm{CH}_{3}\right)$.

UV-Visible data: $\lambda(\mathrm{nm}),\left(\varepsilon\left(\mathrm{M}^{-1} \mathrm{~cm}^{-1}\right): 309.00\right.$ (2360); 255.00 (2590); 243.00 (2740); $238.00\left(2.80 \times 10^{3}\right) ; 233.00(2680) ; 209.00(2470)$.

IR Data: v ( $\mathrm{cm}^{-1}$, intensity); $3176.26(\mathrm{w}) ; 3146.94(\mathrm{w}) ; 3107.57(\mathrm{w}) ; 2974.87(\mathrm{w})$; $1607.42(\mathrm{~m}) ; 1570.00(\mathrm{~m}) ; 1466.61(\mathrm{~m}) ; 1451.44(\mathrm{~m}) ; 1414.46(\mathrm{w}) ; 1376.52(\mathrm{w})$ 1321.97 (w); 1304.35 (m); 1278.42 (m); 1239.78 (m); 1230.43 (s); 1183.09 (m); $1161.80(\mathrm{w}) ; 1130.71(\mathrm{w}) ; 1095.65(\mathrm{w}) ; 1040.82(\mathrm{w}) ; 943.81(\mathrm{~m}) ; 917.36(\mathrm{~m}) ; 876.69$ (m); $836.63(\mathrm{~m}) ; 795.70(\mathrm{w}) ; 766.81(\mathrm{~m}) ; 747.02(\mathrm{~m}) ; 723.67(\mathrm{w}) ; 723.67(\mathrm{w}) ; 686.62$ (w); $660.96(\mathrm{~m}) ; 643.16(\mathrm{w}) ; 636.11(\mathrm{w}) ; 582.93(\mathrm{~m}) ; 560.13(\mathrm{w}) ; 523.31(\mathrm{w}) ; 501.57$ (w); $485.80(w) ; 442.58(w) ; 428.42(w)$.

Synthesis of Bis-[( $\left.\kappa^{3}-S, S, N\right)(2,6$-bis $)\left\{\left[N\right.\right.$-isopropyl- $N^{\prime}$-methylene $]$ triazole-2-thione $\}$ pyridine copper(I) tetrafluoroborate (2)

In a $100 \mathrm{~mL}$ round bottom flask, $0.134 \mathrm{~g}\left(3.44 \times 10^{-4} \mathrm{~mol}\right)$ of $\mathrm{C}_{17} \mathrm{H}_{23} \mathrm{~N}_{7} \mathrm{~S}_{2}$ was combined with $0.0824 \mathrm{~g}\left(3.47 \times 10^{-4} \mathrm{~mol}\right)$ of copper(II) tetrafluoroborate $\left(\mathrm{Cu}\left(\mathrm{BF}_{4}\right)_{2}\right)$ and dissolved in 15. $\mathrm{mL}$ of acetonitrile. The solution was refluxed for 20 hours. During the reaction time, the solution became dark orange. The following day, the solvent was 
removed under reduced pressure. Yield: $0.194 \mathrm{~g}$ (74.8 \%). Pale yellow crystals for Xray diffraction were grown by a slow vapor diffusion of diethyl ether into an acetonitrile solution containing the copper complex. The mass of the titled product after recrystallization was $0.097 \mathrm{~g}(52.2 \%)$.

Anal. Calc. for $\mathrm{C}_{17} \mathrm{H}_{23} \mathrm{CuN}_{7} \mathrm{~S}_{2} \mathrm{BF}_{4}$ (539.89): C, 37.82; H, 4.29; N, 18.16. Found: C, 37.87; H, 4.08; N, 18.09 .

High-resolution electrospray mass spectrometry (positive ion mode) $\mathrm{m} / \mathrm{z}=$ 452.09699 (molecular ion).

High-resolution electrospray mass spectrometry (negative ion mode) $\mathrm{m} / \mathrm{z}=$ 87.01856 (molecular ion).

${ }^{1} \mathrm{H}$ NMR (DMSO-d $\left.6,300 \mathrm{MHz}\right) \delta 9.02(\mathrm{~s}, 2 \mathrm{H}$, triazole $\mathrm{CH}) ; 8.28(\mathrm{~m}, 1 \mathrm{H}$, pyridine $\mathrm{CH}) ;$ $8.01(\mathrm{~m}, 2 \mathrm{H}$, pyridine $\mathrm{CH}) ; 5.55\left(\mathrm{~s}, 4 \mathrm{H}, \mathrm{CH}_{2}\right) ; 4.93$ (septet, $2 \mathrm{H}, 3 \mathrm{~J}=6.6 \mathrm{~Hz}$, isopropyl H); $1.37\left(\mathrm{~d},\left({ }^{3} \mathrm{~J}=6.6 \mathrm{~Hz}\right), 12 \mathrm{H}, \mathrm{iPr} \mathrm{CH}_{3}\right)$.

${ }^{13} \mathrm{C}\left\{{ }^{1} \mathrm{H}\right\}$ NMR (DMSO-d6, $\left.75 \mathrm{MHz}\right), \delta 159.25 ; 153.98 ; 142.28$ (triazole $\mathrm{CH}$ ); 141.59 (pyridine para-CH); 126.43 (pyridine meta- $\mathrm{CH}) ; 51.18\left(\mathrm{H}_{3} \mathrm{CCHCH}_{3}\right) ; 50.10\left(\mathrm{CH}_{2}\right)$; $20.61\left(\mathrm{iPr} \mathrm{CH}_{3}\right)$.

UV-Visible data: $\lambda(\mathrm{nm}),\left(\varepsilon\left(\mathrm{M}^{-1} \mathrm{~cm}^{-1}\right): 278.00(2360) ; 263.00(2470) ; 249.00(2.50 \mathrm{x}\right.$ $\left.10^{3}\right) ; 238.00$ (2590); 231.00 (2530). 
IR Data: v ( $\mathrm{cm}^{-1}$, intensity); 3142.45 (w); $3060.94(w) ; 2983.29$ (w); $2939.16(w)$; $1607.97(\mathrm{w}) ; 1577.61(\mathrm{w}) ; 1542.05(\mathrm{~m}) ; 1485.20(\mathrm{~m}) ; 1452.17(\mathrm{~m}) ; 1432.16(\mathrm{~s}) ;$ 1389.24 (m); 1365.69 (m); 1343.60 (m); 1293.86 (m); 1276.68 (m); 1231.43 (m); 1174.46 (s); 1130.08 (m); 1050.76 (m); 1016.71 (m); 915.70 (m); 876.85 (w); 840.23 (s); 798.67 (m); 769.28 (m); $730.11(\mathrm{~m}) ; 689.47$ (m); 671.40 (m); 657.07 (m); 636.04 (m); 593.85 (m); 538.84 (m); 522.80 (m); 507.14 (m); 488.12 (m); 434.80 (m).

\section{Crystallographic Analyses}

A crystal of $\mathbf{1}$ was mounted on a CryoLoop (Hampton Research) on a Rigaku Oxford diffraction diffractometer at Keene State College (Keene, NH). The crystal was kept at 293(2) K during data collection. Crystallographic data were collected using $1.54184 \mathrm{CuK} \alpha$ radiation. Using Olex2,[26] the structure was solved with the ShelXT[27] structure solution program using intrinsic phasing and refined with the ShelXL[28] refinement package using Least Squares minimization. The crystallographic and refinement data for $\mathbf{1}$ is listed in Table 1. Full details of the Xray structure determination are in the CIF included as supporting information. CCDC data set 1851599 contains the supplementary crystallographic information for this compound. These data can be obtained free of charge from The Cambridge Crystallographic Data Center via www.ccdc.cam.ac.uk/data_request/cif.

A pale yellow block-like crystal platelet of 2 with dimensions 0.12 x $0.14 \times 0.21$ $\mathrm{mm}^{3}$ was secured to a Mitgen micromount using Paratone oil and single crystal X-ray diffraction data was collected using a Rigaku Oxford Diffraction Synergy-S X-ray diffractometer equipped with an ROD HyPix-600HE hybrid photon counting (HPC) 
detector. Data was collected at $100 \mathrm{~K}$ using $\mathrm{Mo} \mathrm{K}_{\alpha 1}$ radiation (= $0.71073 \AA$ Å). A data collection strategy to ensure maximum data redundancy was determined using CrysAlis $^{\text {Pro. }}$ [29] Data processing was done using CrysAlis ${ }^{\text {Pro }}$ and included a multi-scan absorption applied using the SCALE3 ABSPACK scaling algorithm.[30] The crystal was processed as a two-component twin CrysAlis Pro identified a small secondary component rotated after a rendering of the reflections in reciprocal space revealed periodicity indicative of a secondary component rotated by $180^{\circ}$ around the $c$-axis. The data was refined as a 2-component twin. The two components are related by a 180 degree rotation about the $c^{*}$ axis. The fractional volume contribution of the minor twin component was freely refined to a converged value of $0.2018(14)$. The structure was solved using the hklf4 file via intrinsic phasing with ShelXT and final refinements with least squares minimization were completed using the $h k l f 5$ file via ShelXL in the Olex2 graphical user interface.[26-28] The space group was unambiguously verified by PLATON.[31] The final structural refinement included anisotropic temperature factors on all non-hydrogen atoms. Hydrogen atoms were attached via the riding model at calculated positions using appropriate HFIX commands. The crystallographic and refinement data for $\mathbf{2}$ is listed in Table 1. Full details of the X-ray structure determination are in the CIF included as supporting information. CCDC data set 1851600 contains the supplementary crystallographic information for this compound. These data can be obtained free of charge from The Cambridge Crystallographic Data Center via www.ccdc.cam.ac.uk/data_request/cif. 
Table 1. Crystallographic and Refinement Data for $\mathbf{1}$ and 2.

\begin{tabular}{|c|c|c|}
\hline Empirical Formula & {$\left[\mathrm{C}_{19} \mathrm{H}_{25} \mathrm{CuN}_{5} \mathrm{~S}_{2}\right]\left[\mathrm{BF}_{4}\right](\mathbf{1})$} & {$\left[\mathrm{C}_{17} \mathrm{H}_{23} \mathrm{CuN}_{7} \mathrm{~S}_{2}\right]\left[\mathrm{BF}_{4}\right](\mathbf{2})$} \\
\hline Formula weight & 537.91 & 539.89 \\
\hline Temperature (K) & $293(2)$ & $100(2)$ \\
\hline Crystal System & Monoclinic & Triclinic \\
\hline Space Group & $\mathrm{P} 21 / \mathrm{c}$ & $\mathrm{P}-1$ \\
\hline $\mathrm{a} / \AA$ & $10.0395(3)$ & $8.2774(5)$ \\
\hline $\mathrm{b} / \AA$ & $29.1532(5)$ & $10.3763(7)$ \\
\hline c/ $\AA$ & $9.2478(2)$ & $13.7733(7)$ \\
\hline$\alpha /^{\circ}$ & 90 & $88.443(5)$ \\
\hline$\beta /{ }^{\circ}$ & $115.760(3)$ & $79.655(5)$ \\
\hline$\gamma /{ }^{\circ}$ & 90 & $69.147(6)$ \\
\hline Volume / $\AA^{3}$ & $2437.69(11)$ & 1086.64(12) \\
\hline $\mathrm{Z}$ & 4 & 2 \\
\hline Density calc. $\mathrm{g} / \mathrm{cm}^{3}$ & 1.466 & 1.650 \\
\hline$\mu / \mathrm{mm}^{-1}$ & 3.287 & 1.252 \\
\hline $\mathrm{F}(000)$ & 1104.0 & 552.0 \\
\hline Crystal size $/ \mathrm{mm}^{3}$ & $0.18 \times 0.14 \times 0.12$ & $0.21 \times 0.14 \times 0.12$ \\
\hline Radiation & $\mathrm{CuK} \alpha(\lambda=1.54184)$ & $\operatorname{MoK} \alpha(\lambda=0.71073)$ \\
\hline $2 \Theta$ range for data collection $/^{\circ}$ & 9.782 to 142.702 & 5.872 to 50.226 \\
\hline Reflections collected & 9790 & 5667 \\
\hline Independent reflections & $\begin{array}{l}4647\left[R_{\text {int }}=0.0237,\right. \\
\left.R_{\text {sigma }}=0.0337\right]\end{array}$ & $\begin{array}{l}5677 \\
{\left[R_{\text {int }}=0.0295, R_{\text {sigma }}=\right.} \\
0.0513]\end{array}$ \\
\hline Data/restraints/parameters & $4647 / 0 / 306$ & $5677 / 0 / 294$ \\
\hline Goodness-of-fit on $\mathrm{F}^{2}$ & 1.039 & 1.114 \\
\hline Final R indexes $[\mathrm{I}>=2 \sigma(\mathrm{I})]$ & $\mathrm{R}_{1}=0.0455, \mathrm{wR}_{2}=0.1201$ & $\mathrm{R}_{1}=0.0652, \mathrm{wR}_{2}=0.1745$ \\
\hline Final R indexes [all data] & $\mathrm{R}_{1}=0.0564, \mathrm{wR}_{2}=0.1279$ & $\mathrm{R}_{1}=0.0687, \mathrm{wR}_{2}=0.1771$ \\
\hline Largest diff. peak/hole/e $\AA^{-3}$ & $0.99 /-0.54$ & $1.94 /-0.74$ \\
\hline
\end{tabular}




\section{Results and Discussion}

\section{Syntheses and X-ray Crystallography}

The syntheses of $\mathbf{1}$ and $\mathbf{2}$ were accomplished by reacting an acetonitrile solution containing a bis-thione ligand precursor with copper(II) tetrafluoroborate $\left(\mathrm{Cu}\left(\mathrm{BF}_{4}\right)_{2}\right)($ Scheme 1). The reaction happened at reflux temperature in the presence of air in good to excellent yield. Single crystals of $\mathbf{1}$ and $\mathbf{2}$ were obtained by dissolving each compound in acetonitrile and allowing diethyl ether vapor to slowly diffuse into the solution. In general, the complexes are soluble in acetonitrile, methanol, dimethyl sulfoxide, and dichloromethane.

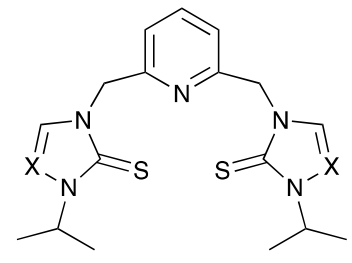

$\mathrm{X}=\mathrm{CH}$ or $\mathrm{N}$

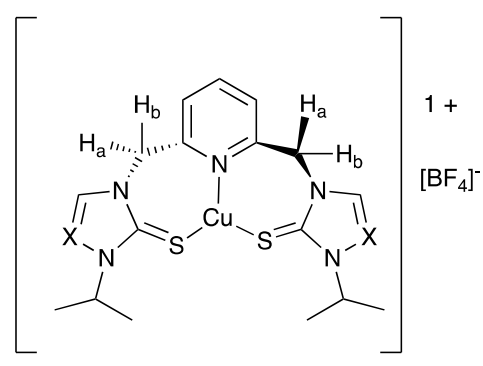

$\mathrm{X}=\mathrm{CH}(1)$

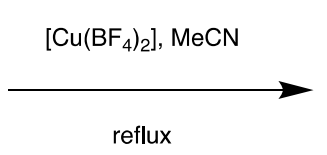

$$
X=N(2)
$$

Scheme 1. Preparation of complexes 1 and 2.

The solid-state structures of $\mathbf{1}$ and $\mathbf{2}$ are shown in Figures 4 and 5, respectively. Both complexes feature pseudo-trigonal planar geometry about the copper(I) metal center with two sulfur and one nitrogen donor atoms coordinated to the copper(I) metal center. Other three-coordinate copper complexes have been reported previously.[32-44] In addition, both complexes feature a non-coordinated tetrafluoroborate counteranion. The $\mathrm{Cu}-\mathrm{S}$ and $\mathrm{Cu}-\mathrm{N}$ bond lengths are almost identical in complexes $\mathbf{1}$ and 2. The Cu-S bond lengths in $\mathbf{1}$ are 2.2253(8) and 2.2202(8) $\AA$ and 
in $\mathbf{2}$ are 2.2150(15) and 2.2231(15) $\AA$. The $\mathrm{Cu}-\mathrm{N}$ bond length is 2.050(2) $\AA$ in $\mathbf{1}$ and 2.008(5) $\AA$ in $\mathbf{2}$. For $\mathbf{1}$ and $\mathbf{2}$, the $\mathrm{Cu}-\mathrm{N}$ bond lengths are similar to those reported previously for three-coordinate copper(I) complexes with trigonal planar geometry. $[39,40]$

The carbon-sulfur bond lengths, 1.712(3) Å and 1.706(3) ̊̊ in $\mathbf{1}$ and 1.703(6) $\AA$ and $1.687(5) \AA$ in 2 , are similar for the two complexes and are between what is normally associated with a C-S single bond $(1.83 \AA)$ and a C=S double bond (1.61 Å).[45] Furthermore, these carbon-sulfur bond distances are 0.02-0.04 $\AA$ shorter than reported by Lobana and co-workers for a thiophosphenyl-bound $\mathrm{Cu}(\mathrm{I})$ complex.[46] We observed disorder in the tetrafluoroborate anion in $\mathbf{1}$, which has been observed previously.[47]

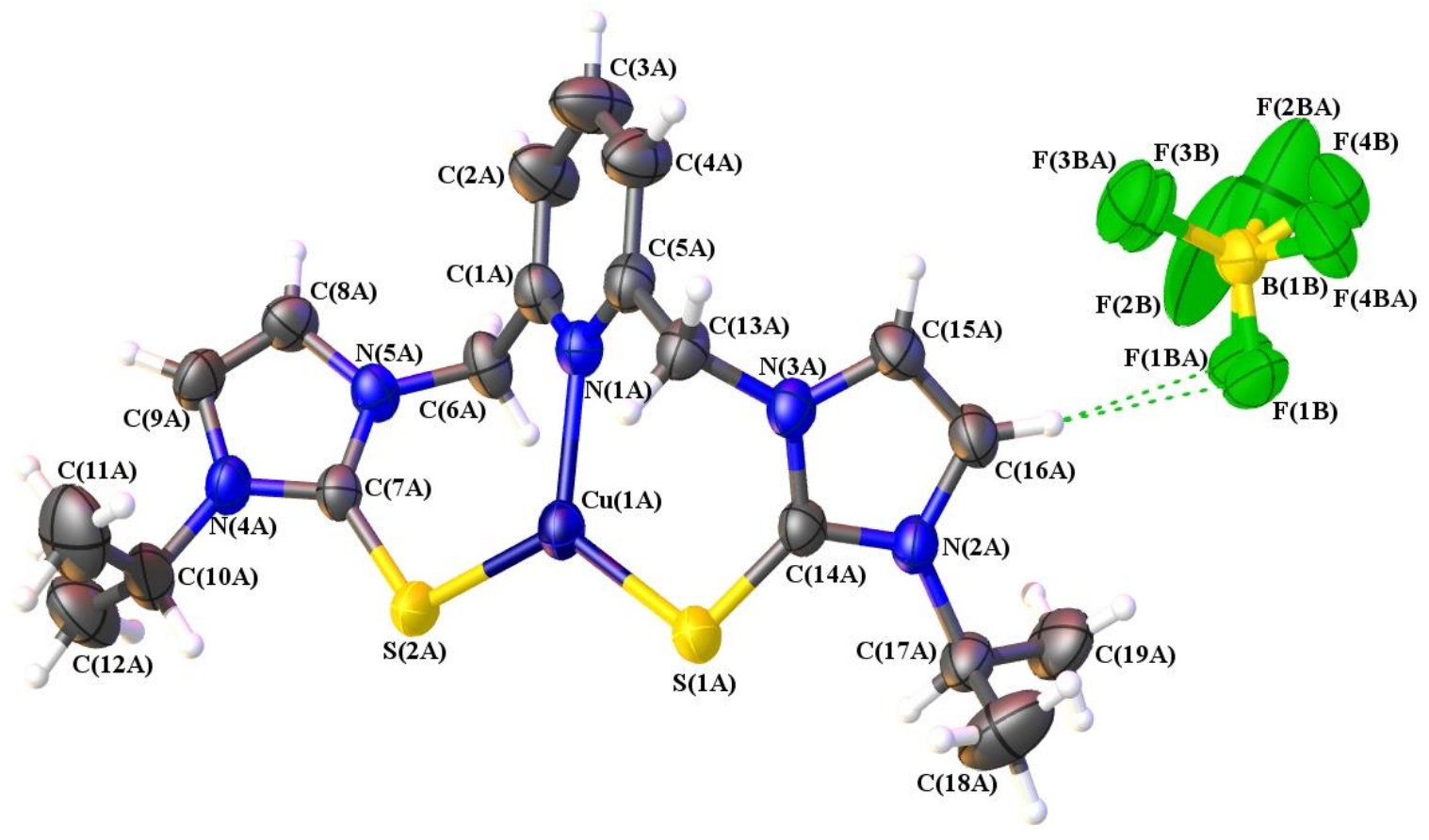

Figure 4. Solid-state structure of 1 . All non-hydrogen atoms shown are depicted with $50 \%$ thermal contours. 
The solid state structures of $\mathbf{1}$ and $\mathbf{2}$ show that the ligands are strongly puckered with the azole rings located on opposite sides of the pyridinyl ring, an orientation enforced by the methylene linkers. The overall structure can therefore be considered as roughly possessing a two-fold axis of rotation that passes through the $\mathrm{Cu}$ center and the pyridinyl $\mathrm{N}$ atom. In complex $\mathbf{1}$, the angle between the planes of the two imidazole rings is $36.5(1)^{\circ}$. The angles between the planes containing the pyridine unit and each of the imidazole rings are $67.65(5)^{\circ}$ and $69.6(1)^{\circ}$. In complex 1, the dihedral angles $\mathrm{Cu}(1 \mathrm{~A})-\mathrm{S}(1 \mathrm{~A})-\mathrm{C}(14 \mathrm{~A})-\mathrm{N}(3 \mathrm{~A})$ and $\mathrm{Cu}(1 \mathrm{~A})-\mathrm{S}(2 \mathrm{~A})-\mathrm{C}(7 \mathrm{~A})-\mathrm{N}(5 \mathrm{~A})$ are $41.9(3)^{\circ}$ and $40.3(3)^{\circ}$, respectively. In complex 2 , the dihedral angles $\mathrm{Cu}(1)-\mathrm{S}(1)$ $\mathrm{C}(7)-\mathrm{N}(3)$ and $\mathrm{Cu}(1)-\mathrm{S}(2)-\mathrm{C}(13)-\mathrm{N}(5)$ are $-37.6(5)^{\circ}$ and $-36.6(5)^{\circ}$, respectively.

The methylene linkers allow for a high S-Cu-S bite angle of $124.38^{\circ}$ and $119.44^{\circ}$ in $\mathbf{1}$ and $\mathbf{2}$, respectively. These are unusually large values for a pincer complex $[47,48]$ but they do act to satisfy a three-coordinate geometry at the metal center nicely, demonstrating the utility of these linkers to allow the pincer ligand to accommodate the binding preference of the metal center. 


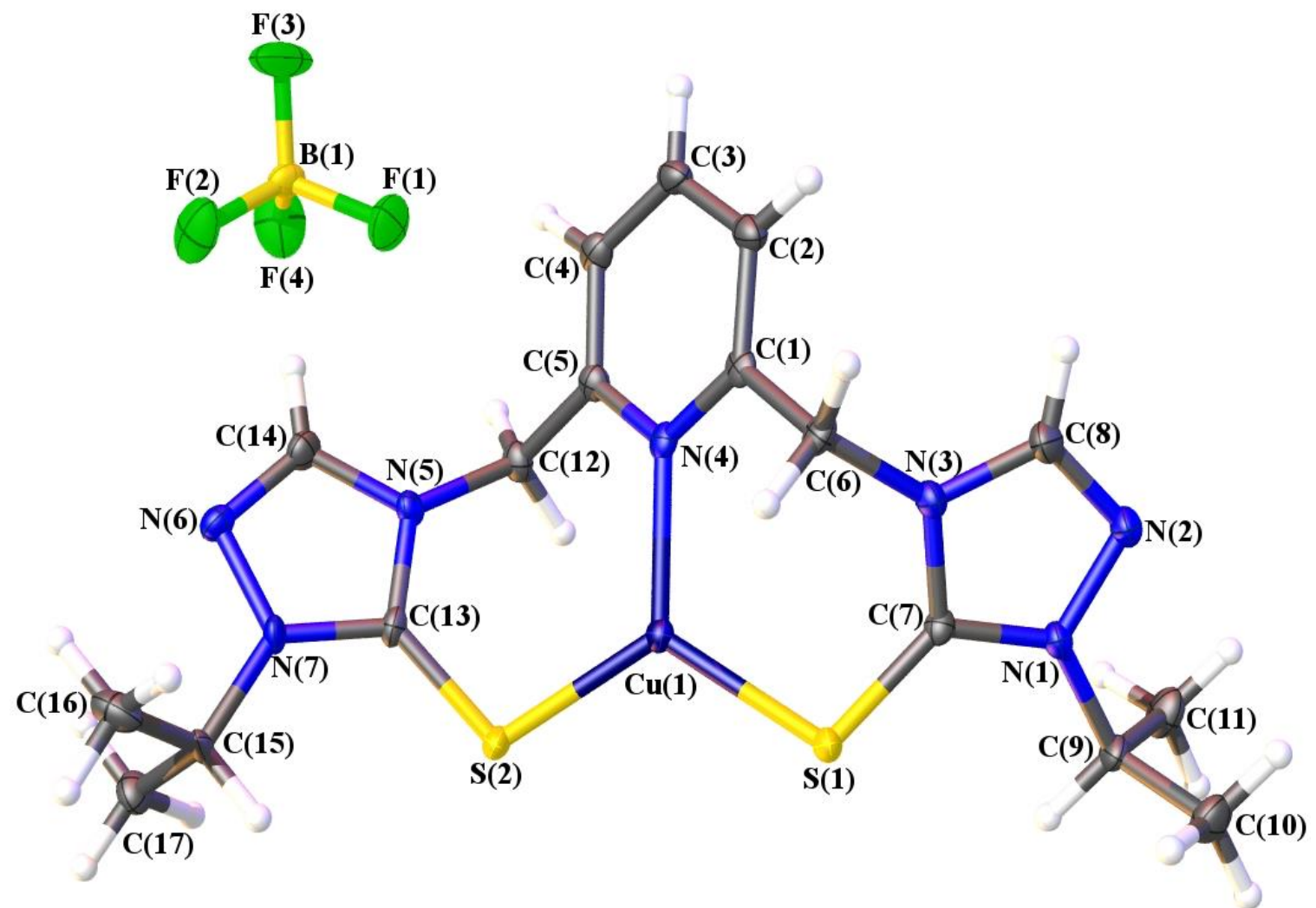

Figure 5. Solid-state structure of $\mathbf{2}$. All non-hydrogen atoms shown are depicted with $50 \%$ thermal contours.

\section{NMR Spectroscopy}

As part of our work, we endeavored to characterize these complexes via ${ }^{1} \mathrm{H}$, ${ }^{13} \mathrm{C}\left\{{ }^{1} \mathrm{H}\right\}$, and HSQC NMR spectroscopy. In order to fully characterize the fluxionality of the protons in $\mathbf{1},{ }^{1} \mathrm{H}$ NMR spectra were acquired at various temperatures in $\mathrm{MeCN}$ $d_{3}$ although several other solvents were investigated as described below. Figure 6 shows these spectra for $\mathbf{1}$ in MeCN-d3. All of the individual ${ }^{1} \mathrm{H}$ NMR spectra acquired are included in the supporting information section. The methylene protons do exist as a pair of resonances at lower temperatures in $\mathrm{MeCN}-\mathrm{d}_{3}$ but upon warming the resonances coalesce, thereby permitting the determination of $\Delta \mathrm{Gexp}^{\ddagger}$. The methylene 
protons therefore appear to be swapping environments by way of some kind of fluxional process.

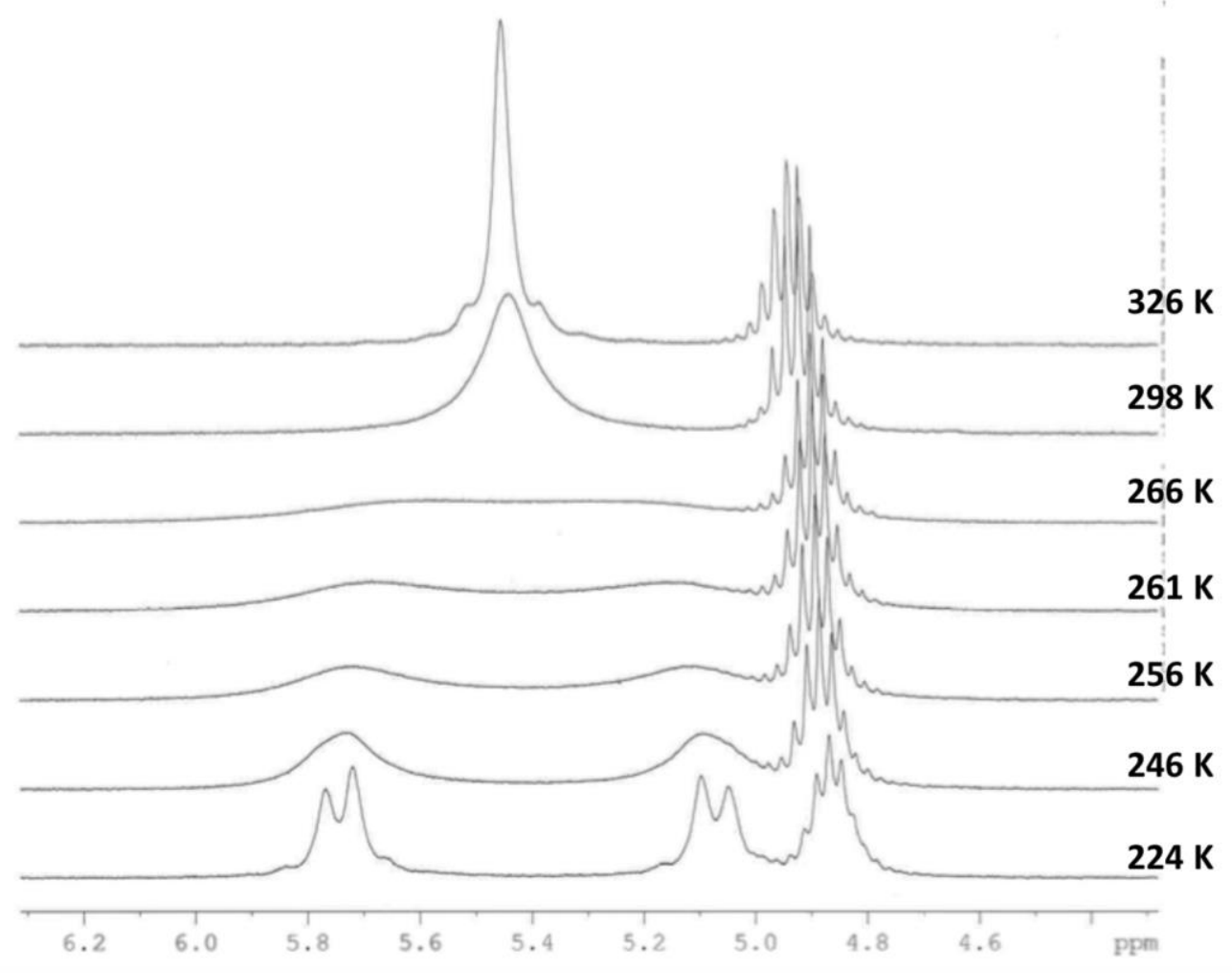

Figure 6. Variable temperature ${ }^{1} \mathrm{H}$ NMR spectra for 1 in $\mathrm{MeCN}-\mathrm{d}_{3}$.

The ${ }^{1} \mathrm{H}$ NMR spectra indicate the presence of residual water. In general, the chemical shift for the water can vary depending on the temperature [49]. In the ${ }^{1} \mathrm{H}$ NMR spectrum for 1, the residual water appears between $\delta 2.35$ and $\delta 2.16 \mathrm{ppm}$. Regarding the presence of water, although the samples could have been recrystallized in anhydrous solvents it was generally difficult to exclude water due to the presence of trace amounts of water in the laboratory environment. 
During this work, several other solvents were investigated with varying degrees of success. The ${ }^{1} \mathrm{H}$ NMR spectrum for $\mathbf{1}$ obtained at $298 \mathrm{~K}$ in DMSO-d6 contains only a single broad methylene resonance at $\delta 5.50 \mathrm{ppm}$. Given that the freezing point of DMSO-d6 is not much lower than this temperature, it was necessary to employ a solvent with a lower melting point than DMSO-d6 to collect data in which the $\mathrm{H}_{\mathrm{a}}$ and $\mathrm{H}_{\mathrm{b}}$ signals could be resolved from each other. As for THF- $\mathrm{d}_{8}$, an insufficient amount of $\mathbf{1}$ dissolved in it. When MeOD-d 3 was used, exchange of the methylene protons of 1 with deuterium from the solvent was evident. Attempts were also made to acquire the variable temperature spectra of $\mathbf{1}$ in $\mathrm{CD}_{2} \mathrm{Cl}_{2}$. At $230 \mathrm{~K}$, two $\mathrm{AB}$ doublets at $\delta 5.85$ and $5.05 \mathrm{ppm}$, representing methylene resonances, were observed. Upon warming to $303 \mathrm{~K}$, the doublets broadened but did not coalesce. At $303 \mathrm{~K}$ the methylene resonances were still separate from each other at $\delta 5.90$ and $\delta 5.12$, thereby preventing a determination of $\Delta \mathrm{G}_{\exp ^{\ddagger}}$.

Provided in Table 2 is a summary of the thermodynamic data for $\mathbf{1}$ as well as for the other experiments conducted as discussed below, including a determination of the change in free energy of the fluxional process $\left(\Delta \mathrm{G}_{\text {exp }}{ }^{\ddagger}\right)$ using the line-broadening method described by Faller [50-52] and of the change in entropy ( $\Delta \mathrm{S}_{\exp ^{\ddagger}}$ ) calculated through construction of an Arrhenius plot (provided with the supplementary information for this article). The rate constants were determined using a method described by Sandström. [53]

Variable temperature ${ }^{1} \mathrm{H}$ NMR data were collected for $\mathbf{1}$ at concentrations of $0.0097 \mathrm{M}$ and $0.0192 \mathrm{M}$ in $\mathrm{MeCN}-\mathrm{d}_{3}$. In both cases, the line-shapes seen at temperatures below the coalescence temperature varied less than $7.0 \mathrm{~Hz}$ at these 
different concentrations, consistent with a common mechanism causing the fluxionality at the two different concentrations.

As with 1, various solvents were investigated for their usefulness in collecting variable temperature NMR data for 2 . In MeCN-d 3 at $298 \mathrm{~K}$, a sharp singlet for the methylene resonance was observed. Upon cooling, the spectrum indicated a broader singlet for the methylene resonance but it was never possible to observe two separate methylene resonances for $\mathbf{2}$ in MeCN-d 3 above $230 \mathrm{~K}$, which is near the freezing point of this solvent. The use of $\mathrm{CDCl}_{3}$ was also attempted, but the solution immediately turned red. This color change was taken to be an indication that complex $\mathbf{2}$ decomposed in this solvent; the decomposition of this product was not further investigated. We also attempted to use THF- $\mathrm{d}_{8}$ but encountered the same solubility issue as with $\mathbf{1}$.

Switching to $\mathrm{CD}_{2} \mathrm{Cl}_{2}$ proved to be more successful, permitting the observation of two resonances for the methylene protons at lower temperatures, but analysis was hampered by the partial overlap of solvent and methylene resonances in 2 . Variable

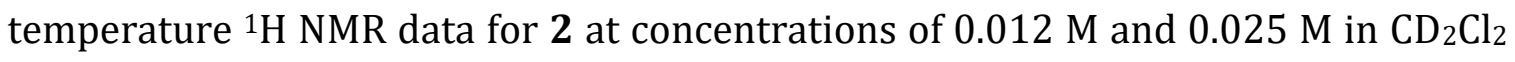
were obtained. In both cases, the line-shapes seen at temperatures below the coalescence temperature varied less then $3.4 \mathrm{~Hz}$ at these different concentrations, consistent with a common mechanism causing the fluxionality at the two different concentrations. However, the need to use $\mathrm{CD}_{2} \mathrm{Cl}_{2}$ as the NMR solvent for $\mathbf{2}$ means that a comparison of the fluxionality of $\mathbf{1}$ and $\mathbf{2}$ in the same solvent cannot be achieved.

Lastly, we wondered if the choice of metal center had an effect on the fluxionality of the complexes, so we attempted to acquire variable temperature ${ }^{1} \mathrm{H}$ 
NMR spectra of bis-imidazole (4a) and bis-triazole (5a) SNS pincer zinc(II) complexes that we have previously prepared.[17] As with $\mathbf{1}$ and 2, both of these Zn(II) systems contain methylene linkers between the pyridine and the azole rings of the pincer ligand. Although we did not observe coalescence of the methylene proton signals for 5a in $\mathrm{MeCN}-\mathrm{d}_{3}$, we did observe coalescence at $266 \mathrm{~K}$ for $4 \mathbf{a}$. Variable temperature ${ }^{1} \mathrm{H}$ NMR data for $[(\mathrm{SNS}) \mathrm{ZnCl}]\left[\mathrm{ZnCl}_{3}\left(\mathrm{OH}_{2}\right)\right]$ (4a) were obtained at concentrations of 0.0075 and $0.01492 \mathrm{M}$ in MeCN-d3. We also attempted to use $\mathrm{CD}_{2} \mathrm{Cl}_{2}$ as the solvent for this experiment but were unable to dissolve enough of the compound to obtain data. For 4a, there was a much broader line shape observed at the higher concentration compared to the lower concentration.

Table 2. Solvent, methylene proton signal coalescence temperature, and experimentally determined $\Delta S^{\ddagger}$ and $\Delta G^{\ddagger}$ for $\mathbf{1}, \mathbf{2}$, and $\mathbf{4 a}$.

\begin{tabular}{|c|c|c|c|c|c|}
\hline Entry & Complex & $\mathbf{T}_{\text {coal }}(\mathrm{K})$ & $\begin{array}{c}\Delta S_{\exp ^{\ddagger}} \\
\left(\mathrm{J} / \mathrm{mol}^{*} \mathrm{~K}\right)\end{array}$ & $\begin{array}{c}\Delta \mathrm{G}_{\text {exp }^{\ddagger}} \\
\left(\mathrm{kJ} / \mathrm{mol}^{\prime}\right)\end{array}$ & Solvent \\
\hline 1 & 1 & 266 & $-61 \pm 2$ & $52 \pm 3$ & $\mathrm{MeCN}-\mathrm{d}_{3}$ \\
\hline 2 & 1 & $>303$ & $\mathrm{~N} / \mathrm{A}$ & $\mathrm{N} / \mathrm{A}$ & $\mathrm{CD}_{2} \mathrm{Cl}_{2}$ \\
\hline 3 & 2 & $<233$ & $\mathrm{~N} / \mathrm{A}$ & $\mathrm{N} / \mathrm{A}$ & $\mathrm{MeCN}-\mathrm{d}_{3}$ \\
\hline 4 & 2 & 298 & $-110 \pm 10$ & $60 \pm 4$ & $\mathrm{CD}_{2} \mathrm{Cl}_{2}$ \\
\hline 5 & $4 a$ & 266 & $-40 \pm 10$ & $51 \pm 4$ & $\mathrm{MeCN}-\mathrm{d}_{3}$ \\
\hline
\end{tabular}




\section{Electrochemistry}

The cyclic voltammograms for $\mathbf{1}$ and $\mathbf{2}$ are included in the supporting information. Table 3 summarizes the oxidation and reduction waves for these complexes at a scan rate of $100 \mathrm{mV} / \mathrm{s}$. All of the waves are irreversible. We have already reported that the ligand precursor for $\mathbf{1}$ showed oxidation features at 976 and $1339 \mathrm{mV}$ [17]. We also reported previously that the ligand precursor for complex 2 showed a single oxidation feature at $1178 \mathrm{mV}$ [17]. For both systems, the oxidation and reduction waves are more complex than what we observed previously for the corresponding ligand precursors.

Table 3. Summary of oxidation and reduction data for $\mathbf{1}$ and $\mathbf{2}$.

\begin{tabular}{|c|c|c|c|}
\hline Complex & $\mathbf{E}_{\text {ox }}(\mathbf{m V})$ & $\mathbf{E}_{\text {red }} \mathbf{( m V )}$ & Solvent \\
\hline $\mathbf{1}$ & $881,563,-417$ & $-769,-1440$ & DMSO \\
\hline $\mathbf{2}$ & $1370,441,-453,-1830$ & $-441,-701,-1010,-1360$, & DMSO \\
\hline
\end{tabular}

\section{Computational Study}

In order to gain a better understanding of the fluxionality that we observed for these complexes, we chose to use the Gaussian 09 software package to investigate a number of possible pathways so that we might propose a mechanism by which the methylene protons of the pincer can become equivalent to each other. Keeping in mind the computational study undertaken previously by Miecznikowski and 
coworkers[15], we believe that we have been able to develop a systematic explanation for our current study that is consistent with these prior results.

We started by taking advantage of the symmetry inherent in the cationic moieties of the $\mathrm{Cu}(\mathrm{I})$ complexes. As can deduced from Figure 4, the $\mathrm{Cu}(\mathrm{I})$-SNS cation has approximate $\mathrm{C}_{2}$ symmetry with one of the imidazole rings located on one side of the plane of the SNS atoms and the other imidazole ring located on the other side such that these two rings are related to each other via a $\mathrm{C}_{2}$ axis of rotation present along the $\mathrm{Cu}-\mathrm{N}$ bond. In our computational study, we have chosen to use a methyl group to represent the alkyl azole pendant functionality. Modeling the Cu(I)-SNS cation with exact $C_{2}$ symmetry has allowed us to determine the relative energies of two pathways depicted in Figure 7: one where the transition state is a flat molecule with $\mathrm{C}_{2 \mathrm{v}}$ symmetry in which the bridging methylenes switch sides of the pyridinyl plane simultaneously (left side of Figure 7), and the other where there is a transition state that possesses $C_{1}$ symmetry in which only one of the methylenes switches sides at a time (right side of Figure 7), thereby giving rise to a stepwise swap of methylene groups. All of these structures are "gas phase" structures in which solvent effects, either through the use of a general solvent potential field or by addition of one or more explicit solvent molecules, are absent. We performed a few calculations with just the generic solvent field turned on and, we found that the energies changed by $\sim 0.4 \mathrm{~kJ} / \mathrm{mol}$, a result similar to that obtained previously.[15]

Although these two pathways do allow for the protons on one of the methylene bridges to become equivalent to those on the other methylene group, the calculated activation energies for the forward and reverse steps do not align with the 
experimental data presented in Table 2. In the "simultaneous-methylene-swap" mechanism, all four of the methylene protons become equivalent to each other in the $\mathrm{C}_{2 \mathrm{v}}$ transition state structure. In the "stepwise-methylene-swap" mechanism, the methylene protons swap equivalencies as the complex passes through the $\mathrm{C}_{2}$ ground state and the $\mathrm{C}_{\mathrm{s}}$ intermediate. In the former, the $\mathrm{C}_{2 \mathrm{v}}$ transition state lies $232 \mathrm{~kJ} / \mathrm{mol}$ above the $\mathrm{C}_{2}$ ground state; in the latter, the $\mathrm{C}_{\mathrm{s}}$ transition state is located $100 \mathrm{~kJ} / \mathrm{mol}$ above the $\mathrm{C}_{2}$ ground state and nearly as much above the $\mathrm{C}_{s}$ intermediate. Both of these energy barriers are well above the $52 \mathrm{~kJ} / \mathrm{mol}$ determined experimentally for $\mathbf{1}$. Examination of several parameters in the optimized structures of the transition states demonstrates why they are so relatively unstable. Bond lengths and angles are indicated in Figure 7. Flattening of the complex to reach the $\mathrm{C}_{2 \mathrm{v}}$ transition state in the simultaneous-swap mechanism while maintaining the threefold SNS coordination sphere of the pincer requires a slight shortening of the $\mathrm{Cu}-\mathrm{S}$ bonds, a considerable reduction in length of the $\mathrm{Cu}-\mathrm{N}$ bond, and a significant hyperextension of both of the $\mathrm{C}_{\text {pyridinyl }}-\mathrm{C}_{\text {methylene- }} \mathrm{N}_{\text {imidazolyl }}$ angles. Flattening of only half of the structure to attain the $\mathrm{C}_{1}$ transition state gives rise to shorter $\mathrm{Cu}-\mathrm{S}$ bonds, a longer $\mathrm{Cu}-\mathrm{N}$ bond, and only one $\mathrm{C}_{\text {pyridinyl }}-\mathrm{C}_{\text {methylene- }} \mathrm{N}$ imidazolyl angle that has been hyperextended. 


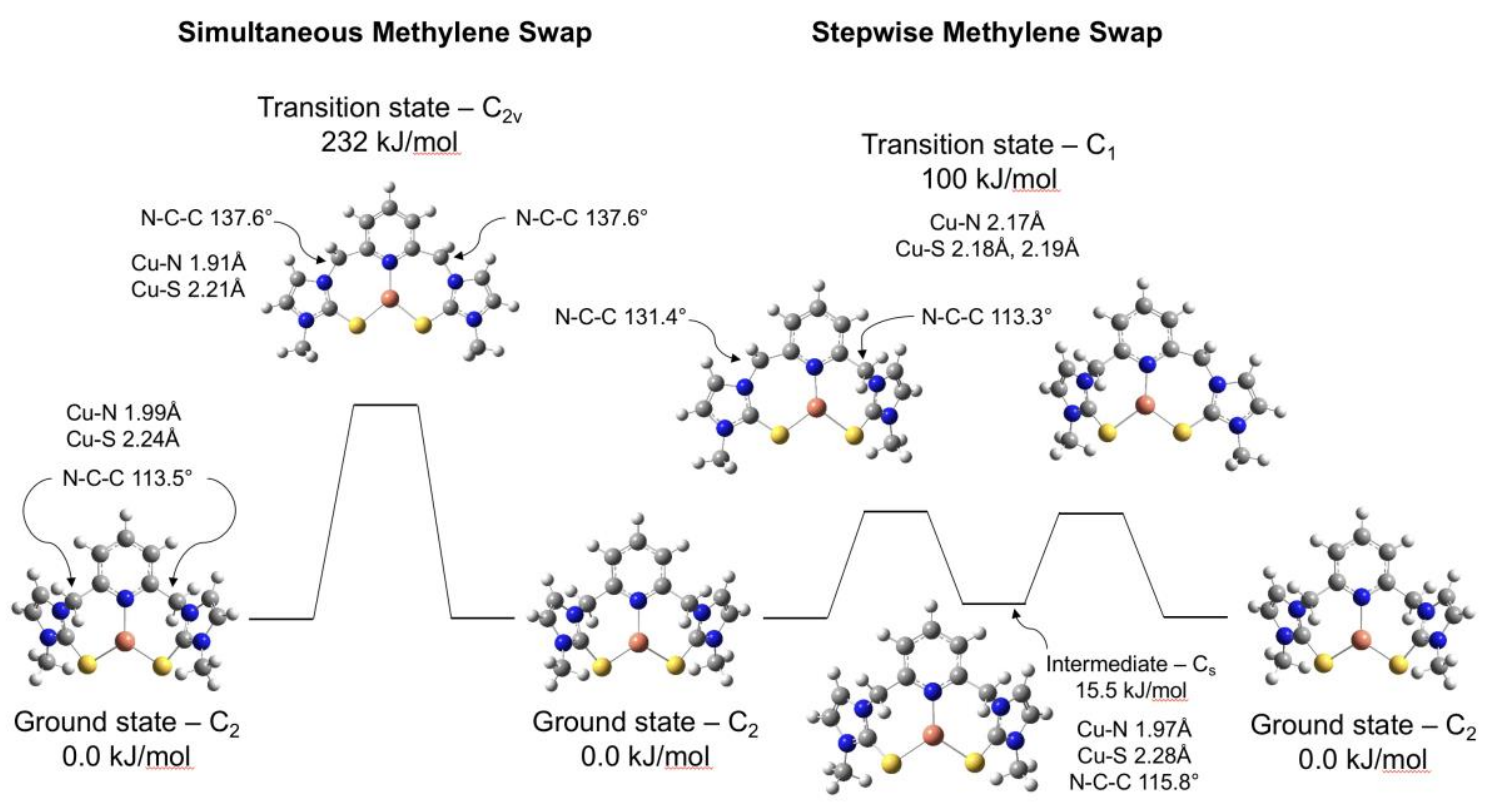

Figure 7. Comparison of the computationally determined solvent-free pathways in which one or both methylene groups swap sides of the SNS plane of the $\mathrm{Cu}(\mathrm{I})$ SNS imidazolyl model system.

We then chose to investigate the influence of a coordinating solvent molecule on the energetics of the fluxionality. In Figure 8, on the left side of the figure is the same gas-phase $\mathrm{C}_{1}$ transition state of the stepwise-swap mechanism shown in Figure 7. On the right side of the figure is a reaction pathway in which the transition state includes an explicit acetonitrile molecule bound to the $\mathrm{Cu}(\mathrm{I})$ center. Our optimization finds that this solvent molecule is strongly bound to the $\mathrm{Cu}$ metal center. In fact, it is so strongly bound ( $\mathrm{Cu}-\mathrm{N}_{\mathrm{MeCN}} 1.98 \AA$ ) that it significantly displaces the $\mathrm{N}_{\text {pyridinyl }}$ atom (Cu- $\mathrm{N}_{\text {pyridinyl }} 2.23 \AA$ ) in the transition state. For comparison, we note that the $\mathrm{Cu}$ $\mathrm{N}_{\text {pyridinyl }}$ bond also lengthened albeit only to $2.17 \AA ̊$ in the analogous gas-phase nonsolvent-coordinated stepwise-swap mechanism shown in Figure 7.

Binding of an acetonitrile molecule to the $\mathrm{Cu}(\mathrm{I})$ center allows the metal center to maintain a three-coordinate environment while simultaneously permitting the 
pyridinyl group to rotate away from the $\mathrm{Cu}(\mathrm{I})$ center, resulting in a slightly more relaxed $\mathrm{C}_{\text {pyridinyl }}-\mathrm{C}_{\text {methylene- }} \mathrm{N}_{\text {imidazolyl }}$ angle $\left(128.9^{\circ}\right.$ vs. $\left.131.4^{\circ}\right)$ than when no solvent molecule is coordinated. As a result of this relaxation, the acetonitrile-coordinated transition state is only $61.1 \mathrm{~kJ} / \mathrm{mol}$ above the combined energies of the $\mathrm{C}_{2}$ ground state and an unbound acetonitrile molecule. Given that the relative energy of the $\mathrm{C}_{\mathrm{s}}$ intermediate is $15.5 \mathrm{~kJ} / \mathrm{mol}$ above the $\mathrm{C}_{2}$ ground state, the solvated transition state is $45.6 \mathrm{~kJ} / \mathrm{mol}$ above the $\mathrm{C}_{\text {s }}$ intermediate. Because the fluxionality proceeds in both directions, we note that the average of these two values ( 61.1 and $45.6 \mathrm{~kJ} / \mathrm{mol}$ ) is 53.4 $\mathrm{kJ} / \mathrm{mol}$, which is remarkably close to the $52 \mathrm{~kJ} / \mathrm{mol}$ found experimentally using NMR spectrometry with this solvent.

Given this result, we propose that coordination of a molecule of acetonitrile to the $\mathrm{Cu}(\mathrm{I})-\mathrm{SNS}_{\text {imidazolyl }}$ system gives rise to hemilability of the SNS pincer ligand, allowing a significant displacement of the pyridinyl fragment that reduces the energy required to cause the atropisomeric interconversion of the methylene protons relative to an unsolvated system. The negative $\Delta \mathrm{S}_{\exp } \neq\left(\mathrm{J} / \mathrm{mol}^{*} \mathrm{~K}\right)$ value for $\mathbf{1}$, shown in Table 2, is consistent with the proposed associative-type mechanism. The importance of considering and using explicit solvent molecules when they behave as coordinating ligands has been emphasized elsewhere and we recognize that the use of a single coordinating solvent molecule is just one step toward modeling a fully solvated system.[54] Yet, we note the closeness of our computed transition state energy to what we have determined experimentally achieved through the incorporation of just one solvent molecule in our model. 
Gas-Phase Pathway

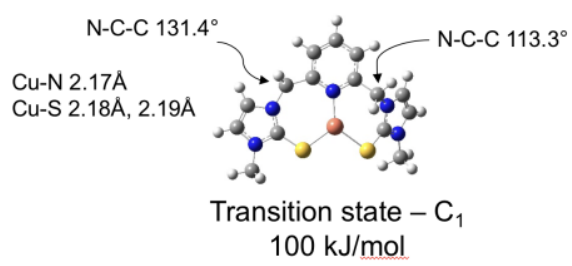

Acetonitrile-Coordinated Transition State Pathway

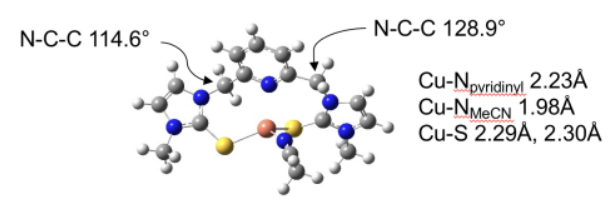

$\mathrm{CH}_{3} \mathrm{CN}$-coordinated transition state $-\mathrm{C}_{1}$ $61.1 \mathrm{~kJ} / \mathrm{mol}$

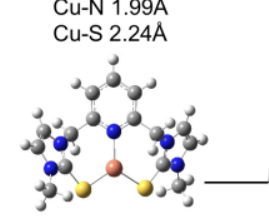

Ground state $-\mathrm{C}_{2}$ $0.0 \mathrm{~kJ} / \mathrm{mol}$

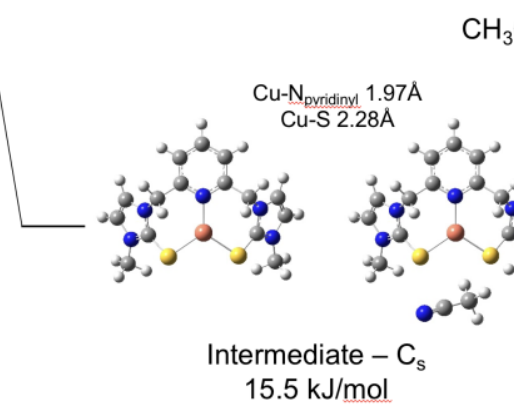

Avg. $53.4 \mathrm{~kJ} / \mathrm{mol}$

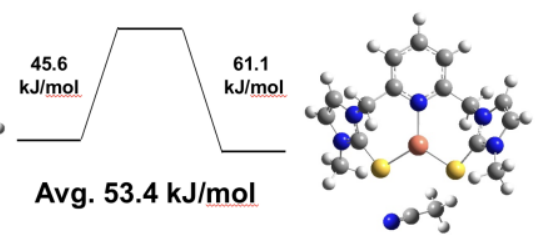

Ground state $-\mathrm{C}_{2}$ $0.0 \mathrm{~kJ} / \mathrm{mol}$

Figure 8. Comparison of the computationally determined stepwise-methyleneswap pathways for the gas-phase and acetonitrile-coordinated $\mathrm{Cu}(\mathrm{I})$-SNSimidazolyl model system.

Having identified a plausible mechanism for the fluxionality of $\mathbf{1}$, we turned our attention to complex $\mathbf{2}$. We first performed calculations similar to those for $\mathbf{1}$ in which the gas-phase simultaneous-swap and stepwise-swap mechanisms were investigated with no explicit solvent molecule bound to the metal center. The energies of the transition states for these two pathways were determined to be 224 $\mathrm{kJ} / \mathrm{mol}$ and $95.8 \mathrm{~kJ} / \mathrm{mol}$, respectively, above the ground state $\mathrm{C}_{2}$-symmetric structure. As indicated in Table 2, the thermodynamic parameters could only be determined using variable temperature $\mathrm{NMR}$ data collected using $\mathrm{CD}_{2} \mathrm{Cl}_{2}$ as the solvent. Regarding the use of acetonitrile as a solvent, we wish to note that its behavior as a coordinating solvent is certainly the same as we have concluded for $\mathbf{1}$ given that we have found that coalescence of the methylene proton signals occurs below $230 \mathrm{~K}$. As for $\mathrm{CH}_{2} \mathrm{Cl}_{2}$, it is known to be a very weakly coordinating solvent [55] and there are 
instances where it has been shown to interact with metal centers.[56] We therefore chose to attempt calculations in which dichloromethane is weakly bonded to the $\mathrm{Cu}$ center in the stepwise-swap interconversion mechanism.

In performing the calculations with a relatively diffuse $\mathrm{Cl}$ basis set (6$311+G(d, p)$ ) employed on the solvent $\mathrm{Cl}$ atoms, we were able to bind one dichloromethane molecule to the $\mathrm{Cu}$ center via one of its $\mathrm{Cl}$ atoms, not both, to generate a stepwise-swap transition state that is $73.6 \mathrm{~kJ} / \mathrm{mol}$ above the $\mathrm{C}_{2}$ ground state and $58.6 \mathrm{~kJ} / \mathrm{mol}$ above the $\mathrm{C}_{\mathrm{s}}$ intermediate. The average of these steps is 66.1 $\mathrm{kJ} / \mathrm{mol}$ as indicated in Figure 9. The $\mathrm{Cu}-\mathrm{N}_{\text {pyridinyl }}$ and $\mathrm{Cu}-\mathrm{Cl}$ distances in the optimized transition state are $2.41 \AA$ and $3.27 \AA$, respectively, both of which are longer than the $\mathrm{Cu}-\mathrm{N}_{\text {pyridinyl }}$ and $\mathrm{Cu}-\mathrm{N}_{\mathrm{MeCN}}$ distances determined for $\mathbf{1}$. We postulate that these longer distances mean that the $\mathrm{Cu}(\mathrm{I})$ center has a less stable coordination environment with $\mathbf{2}$ in the weakly coordinating dichloromethane than with $\mathbf{1}$ in acetonitrile, as evidenced by the fact that the Gaussian- and experimentally determined transition state energies are higher for $\mathbf{2}$ in dichloromethane than for $\mathbf{1}$ in acetonitrile. As was the case for $\mathbf{1}$, the negative $\Delta \operatorname{Sexp}^{\ddagger}\left(\mathrm{J} / \mathrm{mol}^{*} \mathrm{~K}\right)$ value for $\mathbf{2}$ is consistent with the proposed associative-type mechanism. 


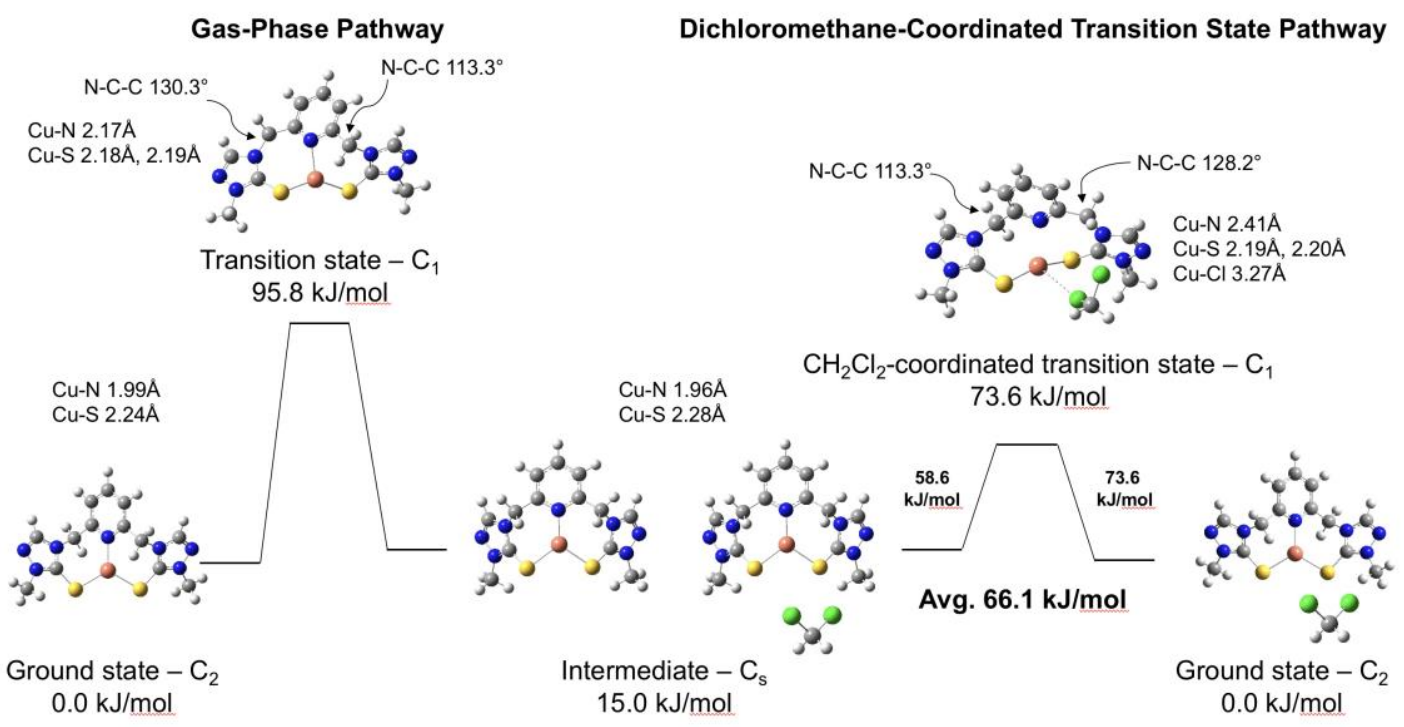

Figure 9. Comparison of the computationally determined stepwise-methylene-swap pathways for the gas-phase and dichloromethane-coordinated $\mathrm{Cu}(\mathrm{I})-\mathrm{SNS}$ triazolyl model system.

Comparing our calculated $\Delta \mathrm{G}^{\ddagger}$ values with those determined experimentally, we note that our calculated value for $\mathbf{1}$ in acetonitrile differs by ca. $3 \%$ from the experimental value whereas that for 2 in dichloromethane differs by 13\%. The difference in quality between these results may be due to the difficulty in obtaining a computational result with a weakly binding solvent, but we also considered experimental factors as well. All of the NMR spectra indicate the presence of water, so we chose to investigate the use of $\mathrm{H}_{2} \mathrm{O}$ as the coordinating solvent molecule in additional Gaussian calculations of the transition state (TS) energy. The water molecule binds to the $\mathrm{Cu}(\mathrm{I})$ center in $\mathbf{2}$ in a fashion that is quite similar to acetonitrile with 1 . The average of the $\mathrm{C}_{2}$-TS and $\mathrm{C}_{s}$-TS energy differences using $\mathrm{H}_{2} \mathrm{O}$ is calculated to be $43.5 \mathrm{~kJ} / \mathrm{mol}$. Considering that the calculated transition state energy for the $\mathrm{Cu}$ SNS(triazolyl) system in dichloromethane is too high by about $8 \mathrm{~kJ} / \mathrm{mol}$, the 
possibility that $\mathrm{H}_{2} \mathrm{O}$ is solvating some of $\mathbf{2}$ would bring the DFT-calculated value more in line with the observed experimental result. In other words, perhaps the $\Delta \mathrm{G}^{\ddagger}$ value we have determined experimentally for $\mathbf{2}$ in dichloromethane is actually the result of $\mathrm{CH}_{2} \mathrm{Cl}_{2}$ solvating some of the molecules and $\mathrm{H}_{2} \mathrm{O}$ solvating others. An additional contributing factor may also be solvation of the available lone pair on the $\mathrm{N}$ atom that is present in the triazolyl rings and not in the imidazolyl functionalities. This interaction is not accounted for in our calculations.

Given what we have concluded from our computational study of the $\mathrm{Cu}(\mathrm{I})$-SNS pincer complexes, we wished to provide a plausible mechanism that explains the fluxionality for 4a. Even before performing calculations analogous to those presented here for the $\mathrm{Cu}(\mathrm{I})$ systems, simple consideration of the four-coordinate pseudotetrahedral environment at the $\mathrm{Zn}(\mathrm{II})$ center and the resulting overall molecular symmetry leads to the conclusion that the methylene protons cannot become equivalent by symmetry, even via the stepwise-methylene-swap mechanism. The presence of the $\mathrm{Zn}-\mathrm{Cl}$ bond means that a $\mathrm{C}_{2}$-symmetric structure is not possible at any point in the kind of fluxional mechanism that we have proposed for the $\mathrm{Cu}(\mathrm{I})$-SNS systems. We therefore opted to investigate two mechanisms computationally as described below.

Our first consideration involved eliminating the chloride ion and attaching two acetonitrile molecules to the $\mathrm{Zn}(\mathrm{II})$ center. In this scenario, the entire $\mathrm{Zn}(\mathrm{II})$ complex has a 2+ charge, the zinc center has a trigonal bipyramidal coordination sphere, and structures with $\mathrm{C}_{2}$ and $\mathrm{C}_{\mathrm{s}}$ symmetry can be reached to allow the methylene protons to become equivalent during the fluxional process. We have no experimental 
evidence to support such a mechanism but we present it here to provide a direct structural comparison to our calculations for $\mathbf{1}$ and $\mathbf{2}$ where the methylene protons can become symmetry-equivalent. The structures we determined computationally for such a pathway are shown in Figure 10. In contrast to our results for the $\mathrm{Cu}(\mathrm{I})$ systems, we note that the $\mathrm{Zn}-\mathrm{N}_{\text {pyridinyl }}$ bond length does not lengthen appreciably, which we attribute to the relatively greater $2+$ charge on the metal center. In the transition state structure, the Zn- $\mathrm{N}_{\text {pyridinyl }}$ bond length is a short $2.03 \AA \AA$, which constrains the motion of the methylene group and leads to a relatively large energy (ca. $100 \mathrm{~kJ} / \mathrm{mol}$ ) required to reach this structure.

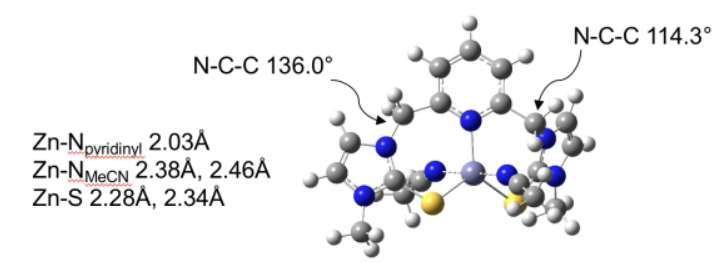

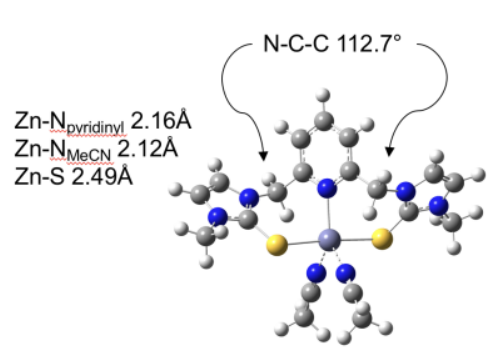

Ground state $-\mathrm{C}_{2}$ $0.0 \mathrm{~kJ} / \mathrm{mol}$

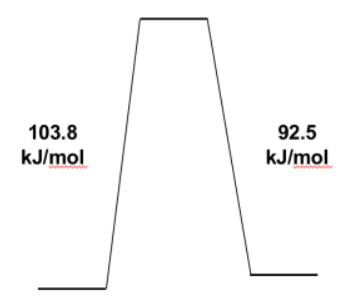

Avg. $98.2 \mathrm{~kJ} / \mathrm{mol}$

$$
\begin{gathered}
\text { Intermediate }-\mathrm{C}_{\mathrm{s}} \\
+11.3 \mathrm{~kJ} / \mathrm{mol}
\end{gathered}
$$

Figure 10. Computationally determined fluxional pathway involving a fivecoordinate, bis(acetonitrile)-bound $\mathrm{Zn}(\mathrm{II})$ center with $\mathrm{C}_{2}$-and $\mathrm{Cs}$-symmetric lower energy structures. The $\mathrm{Cl}$ ligand has been lost to allow for the methylene protons to become equivalent by symmetry.

Figure 11 shows an alternate mechanism in which the $\mathrm{Zn}-\mathrm{Cl}$ bond remains intact throughout the fluxional process. The total charge on the system is therefore 
$1+$ and the pathway more closely resembles that proposed for the $\mathrm{Cu}(\mathrm{I})$ systems. One equivalent of acetonitrile displaces the pyridinyl $\mathrm{N}$ atom in the transition state ( $\mathrm{Zn}$ $\mathrm{N}_{\text {pyridinyl }} 3.42 \AA$ ), maintaining a four-coordinate $\mathrm{Zn}$ center throughout with the acetonitrile molecule bound quite tightly (Zn-N $\mathrm{N}_{\mathrm{MeN}} 2.12 \AA$ ). The transition state is an average of $59.2 \mathrm{~kJ} / \mathrm{mol}$ above the lower energy structures, a value that is much more in line with what we observed experimentally.

Overall, we favor the mechanism provided in Figure 11, where the $\mathrm{Zn}-\mathrm{Cl}$ bond remains intact, but it does raise a question about the need for the methylene protons to become perfectly equivalent by symmetry in order for the ${ }^{1} \mathrm{H}$ NMR resonance to coalesce. Regarding the pathway presented in Figure 10, it seems unlikely that the $\mathrm{Zn}-\mathrm{Cl}$ would break to give a cation with a more positive charge. In fact, for the $\mathrm{Pd}(\mathrm{II})$ CNC systems studied previously,[15] outright loss of the inner-sphere ion without replacement by an outer-sphere ion was not proposed to explain the fluxionality. As for the mechanism in Figure 11, it shows that an acetonitrile molecule clearly displaces the pyridinyl group whereas the mechanism in Figure 10 actually shows the Zn- $\mathrm{N}_{\text {pyridinyl }}$ bond getting shorter. The pathway in Figure 11 is therefore more consistent with what we are proposing for the Cu-SNS systems. The negative $\Delta \mathrm{Sexp}^{*}$ found for this complex is also more in line with the mechanism shown in Figure 11 in which a solvent molecule associates with the metal center in the transition state whereas in Figure 10 there is no clear change in the $\mathrm{Zn}$ coordination sphere for this mechanism. Further, an important outcome from this proposal is that symmetry does not need to be reached in order for the $\mathrm{CH}_{2}$ protons to become equivalent. We conclude that the observed coalescence is a result of the nearly, but not perfectly, 
equivalent environments of the methylene protons as the solvent displaces the pyridinyl moiety, causing the molecule to contort.

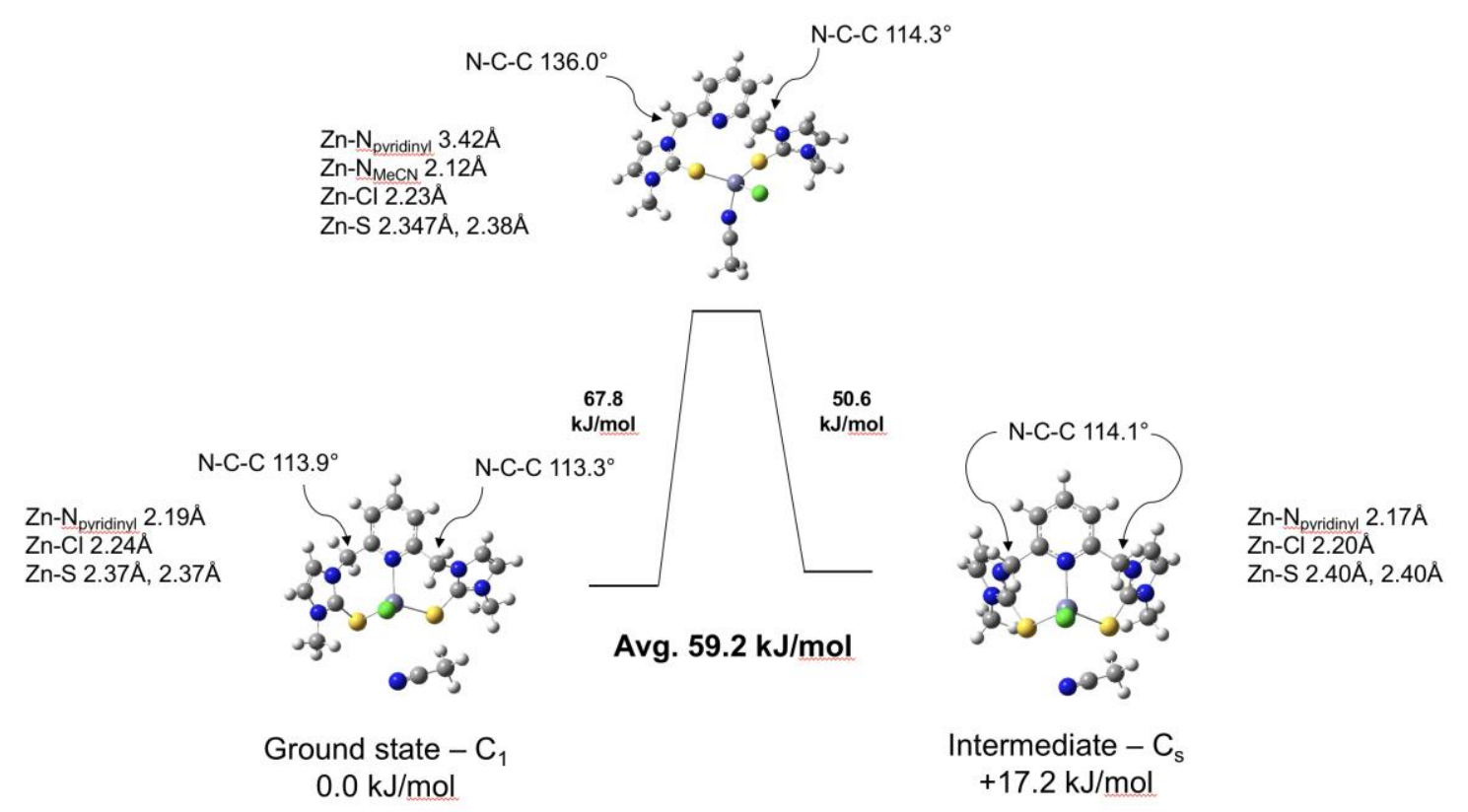

Figure 11. Computationally determined fluxional pathway involving a fourcoordinate acetonitrile-bound $\mathrm{Zn}$ (II) center and preservation of the $\mathrm{Zn}-\mathrm{Cl}$ bond throughout.

Lastly, we wish to compare the findings of our current work in light of those proposed previously for Pd(II) CNC pincer complexes.[15] The general mechanistic pathway for the observed fluxionality involving the hemilability of the pincer's pyridinyl group is similar for all of these systems. We note that in both reports, the experimentally observed transition state energies are all found at ca. $50-70 \mathrm{~kJ} / \mathrm{mol}$, suggesting the possibility of a similar pathway in all instances. For the palladium systems, the metal atom's four-fold square planar coordination sphere was composed of the tridentate pincer ligand and an inner sphere anion $\left(\mathrm{X}_{\mathrm{IS}}\right)$. To displace the 
pyridine moiety, thereby providing a lower energy pathway for the methylene group to rotate to the opposite side of the plane pyridinyl group, it was proposed that an outer sphere anion (Xos) acts as a reasonably strong nucleophile and coordinates to the metal center via an associative substitution pathway. This effect was described as "effectively intramolecular" within a [MXIS]-Xos tight ion pair in solution. In our current work, the counteranions $\left(\left[\mathrm{BF}_{4}\right]\right.$ - for $\mathbf{1}$ and $\mathbf{2}$, $\left[\mathrm{ZnCl}_{3}\left(\mathrm{OH}_{2}\right)\right]^{-}$for $\left.\mathbf{4 a}\right)$ cannot be expected to be strongly nucleophilic. In the absence of a coordinating anion, a solvent molecule can act as a nucleophile that binds to the $\mathrm{Cu}(\mathrm{I})$ and $\mathrm{Zn}(\mathrm{II})$ metal centers, displacing the pyridinyl group. We even conclude here that a generally noncoordinating solvent such as dichloromethane can also give rise to this effect. For the Pd(II) systems the presence of the weakly coordinating tosylate Xos anion gave rise to relatively higher activation energies just as we observe and calculate here for the weakly coordinating dichloromethane.

Given our determination that the solvent is involved in displacing the pyridinyl group, we wish to comment specifically on the role of the solvent as it was described for the Pd(II) CNC fluxionality. It was observed that the rate of the fluxional process for the palladium systems was independent of the solvent (CDCl 3 vs. DMSO-d6)[12] except for $\left[\{\mathrm{CNC}\} \mathrm{Pd}\left(\mathrm{OH}_{2}\right)\right]\left[\mathrm{BF}_{4}\right]_{2}$ for which $\Delta \mathrm{G}^{\ddagger}$ was greater in $\mathrm{CDCl}_{3}(>73 \mathrm{~kJ} / \mathrm{mol})$ than in DMSO- $\mathrm{d}_{6}(68.5 \mathrm{~kJ} / \mathrm{mol}) .[15]$ This latter determination is in line with the general theme of our current findings. Computationally, the previous report described examination of the effect on the activation energy by the solvent through the use of a continuum model with the conclusion that it had "very little effect on the energy pattern." Given the presence of both XIs and Xos for the Pd(II) systems, we can 
understand how solvent would have relatively little effect given the expected greater attraction of the negatively charged $\mathrm{X}_{\text {os }}$ ion to the $\left[\{\mathrm{CNC}\} \mathrm{PdX} \mathrm{X}_{\mathrm{s}}\right]^{+}$cation. As described in the previous report, "the polarity of the solvent has little direct consequence on a fluxional process occurring within a $\left[\{\mathrm{CNC}\} \mathrm{PdX}_{\mathrm{IS}}\right] \mathrm{X}_{\text {os }}$ tight ion pair." [15] However, in the absence of such a coordinating outer sphere anion as we have in our current study, explicit inclusion of a solvent molecule rather than application of a solvation field without discrete solvent molecular units in the modeling calculations is necessary to fully describe the transition state structure.

\section{Conclusions}

We have reported herein the syntheses and detailed characterizations (X-ray crystallography, NMR spectroscopy, cyclic voltammetry, infrared spectroscopy, electrospray mass spectrometry, and elemental analyses) of tridentate pincer complexes that coordinate to copper(I) metal centers. The copper(I) complexes have pseudo-trigonal planar geometry about the metal center and the relatively noncoordinating tetrafluoroborate as a counteranion. The pincer ligand, which contains pyridinyl and thione-substituted imidazole or triazole functionalities, coordinates to the copper(I) cation through the sulfur and nitrogen donor atoms of these groups.

Our variable temperature ${ }^{1} \mathrm{H}$ NMR studies show that our newly prepared copper(I) complexes are fluxional and have allowed us to determine $\Delta \mathrm{G}_{\exp }{ }^{\ddagger}$ and $\Delta \mathrm{S}_{\exp ^{\ddagger}}$ for this process. To model the fluxionality, we have used Gaussian calculations to propose an associative mechanism that explains this behavior. A solvent-induced hemilability of the SNS pincer's pyridinyl group occurs whereas the $\mathrm{Cu}-\mathrm{S}$ bonds 
remain intact during the process. Our Gaussian results are nicely consistent with our $\Delta \mathrm{G}_{\exp ^{\ddagger}}$ and $\Delta \mathrm{S}_{\exp ^{\ddagger}}$ values. A coordinating solvent such as acetonitrile can displace the pyridinyl unit, providing the methylene groups that link the pincer's pyridinyl and azole rings with a lower energy pathway by which they can rotate to the opposite side of the plane of the pyridinyl group. This motion allows the methylene protons to become equivalent to each other resulting in the coalescence observed here for the $\mathrm{Cu}(\mathrm{I})$ systems and previously for $\mathrm{Pd}(\mathrm{II}) \mathrm{CNC}$ complexes. For our $\mathrm{Zn}(\mathrm{II})$ complex, we propose that a similar fluxional pathway occurs although the methylene protons cannot become perfectly equivalent by symmetry due to the presence of the chloride ligand that is bound to the $\mathrm{Zn}(\mathrm{II})$ center. In this case, we postulate that the environments of the methylene protons are similar enough during the fluxional pathway that their resonances also coalesce on the ${ }^{1} \mathrm{H}$ NMR timeframe. Future work will focus on the reactivity of these copper(I) and zinc(II) complexes to further elucidate their properties.

\section{Conflicts of interest}

There are no conflicts of interest to declare.

\section{Acknowledgements}

MAL thanks NTID for a Faculty Evaluation and Development (FEAD) grant. JRM is grateful for the generous support from the Connecticut NASA Space Grant Alliance for this project (Award Number P-1168). JRM also thanks the National Science Foundation CHE-1827854 for the acquisition of a $400 \mathrm{MHz}$ NMR Spectrometer and Mr. Tim Bergeron at JEOL-USA for performing line-shape analysis. 
JPJ acknowledges the NSF-MRI program (Grant Number CHE-1039027) for funds to purchase the X-ray diffractometer. EMA and RMK acknowledge the Hardiman Scholars Program for supporting their summer research stipend. JRM would like to thank Mr. Terence Wu for assistance in acquiring electrospray mass spectra and Prof. Amanda Harper-Leatherman for assistance in acquiring cyclic voltammograms. JRM would also like to acknowledge the Prof. Timothy Curran at Trinity College (Hartford, CT) for assistance in acquiring $400 \mathrm{MHz}$ Variable Temperature NMR data (CHE0619275) and Prof. Robert Crabtree at Yale University (New Haven, CT) for helpful discussions during the development of this manuscript. 


\section{References:}

1. a) C. Gunanathan, D. Milstein, Chem. Rev. 2014, 114, 12024-12087; b) Pincer Compounds: Chemistry and Applications (Ed.: D. Morales-Morales), Elsevier, Amsterdam, 2018; c) Pincer and Pincer-Type Complexes: Applications in Organic Synthesis and Catalysis (Eds.: K. J. Szabo, O. F. Wendt), Wiley-VCH, Weinheim, 2014; d) M. Assay, D. Morales-Morales, Dalton Trans. 2015, 44, 17432-17447; e) The Chemistry of Pincer Compounds (Eds.: D. MoralesMorales, C. M. Jensen), Elsevier, Amsterdam, 2007; f) H. Valdes, L. GonzálezSebastián, D. Morales-Morales, J. Organomet. Chem. 2017, 845, 229-257; g) V. Gómez-Benítez, H. Valdés, S. Hernández-Ortega, J. Manuel German-Acacio, D. Morales-Morales, Polyhedron 2018, 143, 144-148; h) H. Valdes, M. A. GarcíaEleno, D. Canseco-Gonzalez, D. Morales-Morales, ChemCatChem 10.1002/cctc.201702019; i) Organometallic Pincer Chemistry (Eds.: G. van Koten, D. Milstein), Springer, Berlin, 2013; j) The Privileged Pincer-Metal Platform: Coordination Chemistry \& Applications (Eds.: G. van Koten, R. A. Gossage), Springer, Berlin, 2015; k) M. Basauri-Molina, S. Hernández-Ortega, D. Morales-Morales, Eur. J. Inorg. Chem. 2014, 4619-4625; l) M. A. W. Lawrence, K.-A. Green, P. N. Nelson, S. C. Lorraine, Polyhedron 2018, 143, 1127.

2. E. Peris, R. H. Crabtree, Coord. Chem. Rev. 2004, 248, 2239-2246.

3. M. Asay, D. Morales-Morales, Dalton Trans. 2015, 44, 17432-17447.

4. E. Peris, R. H. Crabtree, Chem. Soc. Rev. 2018, 47, 1959-1968.

5. L. Ma, P. M. Imbesi, J. B. Updegraff III, A. D. Hunter, J. D. Protasiewicz, Inorg. Chem. 2007, 46, 5220-5228.

6. K. R. Pichaandi, L. Kabalan, S. Kais, M. M. Abu-Omar, J. Organomet. Chem. 2017, 843, 62-65.

7. D. Ghorai, S. Kumar, G. Mani, Dalton Trans. 2012, 41, 9503-9512.

8. Y. Kawada, Y. Kataoka, Y. Ura, Dalton Trans. 2013, 42, 14844-14855.

9. C. Mazet, L. H. Gade, Chem. Eur. J. 2003, 9, 1759-1767.

10. Y. Klerman, E. Ben-Ari, Y. Diskin-Posner, G. Leitus, L. J. W. Shimon, Y. Ben-David, D. Milstein, Dalton. Trans. 2008, 3226-3234.

11. C. A. Kruithof, H. P. Dijkstra, M. Lutz, A. L. Spek, R. J. M. Klein Gebbink, G. von Koten, Organometallics 2008, 27, 4928-4937. 
12. S. Gründemann, M. Albrecht, J.A. Loch, J.W. Faller, R. H. Crabtree, Organometallics 2001, 20, 5485-5488.

13. J.C. Jeffrey, T.B. Rauchfuss, Inorg. Chem. 1979, 18, 2658-2666.

14. P.M. Perez Garcia, P. Ren, R. Scopelliti, X. Hu, ACS Catal. 2015, 5, 1164-1171.

15. J.R. Miecznikowski, S. Gründemann, M. Albrecht, C. Mégret, C., E. Clot, J.W. Faller, O. Eisenstein, R.H. Crabtree, Dalton Trans. 2003, 831-838.

16. J.R. Miecznikowski, W. Lo, M.A. Lynn, B.E. O'Loughlin, A. P. DiMarzio, A.M. Martinez, L. Lampe, K.M. Foley, L.C. Keilich, G.P. Lisi, D.J. Kwiecien, C.M. Pires, W.J. Kelly, N.F. Kloczko, K.N. Morio, Inorg. Chim. Acta 2011, 376, 515-524.

17. J.R. Miecznikowski, W. Lo, M.A. Lynn, S. Jain, L.C. Keilich, N.F. Kloczko, B.E. O'Loughlin, A.P. DiMarzio, K.M. Foley, G.P. Lisi, D.J. Kwiecien, E.E. Butrick, E. Powers, R. Al-Abbasee, Inorg. Chim. Acta 2012, 387, 25-36.

18. K.K. Kannan, B. Nostrand, K. Fridborg, S. Lovgren, A. Ohlsson, M. Petef, Proc. Natl. Acad. Sci. USA 1975, 72, 51.

19. J.R. Miecznikowski, M.A. Lynn, J.P. Jasinski, E. Reinheimer, D. Bak, M. Pati, E.E. Butrick, A.E.R. Drozdoski, K.A. Archer, C.E. Villa, E.G. Lemons, E. Powers, M. Siu, C.D. Gomes, K.N. Morio, J. Coord. Chem. 2014, 67, 29-44.

20. J.R. Miecznikowski, M.A. Lynn, J.P. Jasinski, W. Lo, D. Bak, M. Pati, E.E. Butrick, A.E.R. Drozdoski, K.A. Archer, C.E. Villa, E.G. Lemons, E. Powers, M. Siu, C.D. Gomes, N.A. Bernier, K.N. Morio, Polyhedron 2014, 80, 157-165.

21. A.A. Grindev, I.M Mihaltseva, Synth. Commun. 1994, 24, 1547-1555.

22. P.G. Bulger, I.F. Cottrell, C.J. Cowden, A.J. Davies, U-H. Dolling, Tetrahedron Lett. 2000, 41, 1297-1301.

23. C. Amman, P. Meier, A. E. Merbach, J. Magn. Reson. 1982, 46, 319-321.

24. M.J. Frisch, G.W. Trucks, H.B. Schlegel, G.E. Scuseria, M.A. Robb, J.R. Cheeseman, G. Scalmani, V. Barone, G.A. Petersson, H. Nakatsuji, X. Li, M. Caricato, A. Marenich, J. Bloino, B.G. Janesko, R. Gomperts, B. Mennucci, H.P. Hratchian, J.V. Ortiz , A.F. Izmaylov, J.L. Sonnenberg, D. Williams-Young, F. Ding, F. Lipparini, F. Egidi, J. Goings, B. Peng, A. Petrone, T. Henderson, D. Ranasinghe, V.G. Zakrzewski, J. Gao, N. Rega, G. Zheng, W. Liang, M. Hada, M. Ehara, K. Toyota, R. Fukuda, J. Hasegawa, M. Ishida, T. Nakajima, Y. Honda, 0. Kitao, H. Nakai, T. Vreven, K. Throssell, J. A. Montgomery Jr, J.E. Peralta, F. Ogliaro, M. Bearpark, J.J. Heyd, E. Brothers, K. N. Kudin, V.N. Staroverov, T. Keith, R. Kobayashi, J. Normand, K. Raghavachari, A. Rendell, J.C. Burant, S.S. 
Iyengar, J. Tomasi, M. Cossi, J.M. Millam, M. Klene, C. Adamo, R. Cammi, J.W. Ochterski, R.L. Martin, K. Morokuma, O. Farkas, J.B. Foresman, D.J. Fox. (2013) Gaussian 09, Revision D.01, Gaussian, Inc.: Wallingford CT.

25. J.R. Miecznikowski, J.P. Jasinski, M.A. Lynn, S.S. Jain, E.E. Butrick, A.E.R. Drozdoski, K.A. Archer, J.T. Panarra, Inorg. Chim. Acta 2013, 394, 310-321.

26. O.V. Dolomanov, L.J. Bourhis, R.J. Gildea, J.A.K. Howard, H. Puschmann, J. Appl. Crystallogr. 2009, 42, 339-341.

27. G.M. Sheldrick, Acta Crystallogr. 2015, A71, 3-8.

28. G.M. Sheldrick, Acta Crystallogr. 2015, C71, 3-8.

29. CrysAlisPro, Rigaku Oxford Diffraction, 2017,version 171.39.27b.

30. SCALE3 ABSPACK - A Rigaku Oxford Diffraction program for Absorption Corrections, Rigaku Oxford Diffraction, 2017.

31. A.L. Spek, Acta Crystallogr. 2009, D65, 148.

32. V.A. Krylova, P.I. Djurovich, J.W. Aronson, R. Haighes, M.T. Whited, M. E. Thompson, Organometallics 2012, 31, 7983-7993.

33. C.C. Chou, H.-J. Liu, L. H-C. Chao, H.-C. Syu, T.-S. Kuo, Polyhedron 2012, 37, 6065.

34. M. Hashimoto, S. Igawa, Y. Satoshi, K. Masataka, I. Kawata, M. Hoshino, M. Osawa, J. Am. Chem. Soc. 2011, 133, 10348-10351.

35. T.S. Lobana, P.S. Kumari, C. Rekha, A. Castineiras, R.J. Butcher, T. Akitsu, Y. Aritake, Dalton Trans. 2011, 40, 3219-3228.

36. C.C. Chou, H.-J. Liu, L. H.-C. Chao, Chemical Commun. 2009, 6382 -6384.

37. B.A. Gandhi, O. Green, J.N. Burstyn, Inorg. Chem. 2007, 46, 3816-3825

38. M. A. S. Goher, T.C.W. Mak, Polyhedron 1998, 17, 3485-3494.

39. M. Munakata, M. Maekawa, S. Kitagawa, S. Matsuyama, H. Masuda. Inorg. Chem. 1989, 28, 4300-4302.

40. T.N. Sorrell, M.R. Malachowski, Inorg. Chem. 1983, 22, 1883-1887.

41. J.A. Tiethof, A.T. Hetey, D.W. Meek, Inorg. Chem. 1974, 13, 2505-2509. 
42. J.A. Tiethof, A.T. Hetey, P.E. Nicpon, D.W. Meek, Inorg. Nucl. Chem. Lett. 1972, 8, 841-844.

43. F. Kiyoshi, N. Yuki, M. Yoshitaro, O. Ken-Ichi, L. Nicolai, Inorg. Chem. 2007, 46, 10607-10623.

44. C. G. Palvan, S. Ramaprabhu, J. Chem. Soc., Dalton Trans. 2000, 3513-3518.

45. B. V. Trzhtsinskaya, N. D. Abramova, J. Sulfur Chem. 1991, 10, 389-421.

46. T.S. Lobana, G. Singh, T. Nishioka, J. Coord. Chem. 2004, 57, 955-960.

47. D. F. Mullica, S.L. Gipson, E.L. Sappenfield, C.C. Lin, D.H. Leschnitzer, Inorg. Chim. Acta 1990, 177, 89-96.

48. M. Winston, J.E. Bercaw, Inorg. Chim. Acta 2014, 422, 30-35.

49. G. R. Fulmer, A. J. M. Miller, N. H. Sherden, H. E. Gottlieb, A. Nudelman, B. M. Stoltz, J. E. Bercaw, K. I. Goldberg, Organometallics 2010, 29, 2176-2179.

50. M. E. Pascualini, N. V. Di Russo, A. E. Thuijs, A. Ozarowski, S. A. Stoian, K.A. Abboud, G. A. Christou, A. S. Veige. Chem. Sci. 2015, 6, 608.

51. E. W. Abel, K. G. Orrell in Encyclopedia of Inorganic Chemistry (Ed.: R. B. King), John Wiley and Sons, New York, 1994, pp. 2581-2615.

52. J. W. Faller in Encyclopedia of Inorganic Chemistry (Ed.: R. B. King), John Wiley and Sons, New York, 1994, pp. 3914-3933.

53. Sandström, J. Dynamic NMR Spectroscopy. 1982, Academic Press: New York, p. 78.

54. J. del Pozo, M. Pérez-Iglesias, R. Álvarez, A. Lledós, J. A. Casares, P. Espinet, ACS Catalysis 2017, 7, 3575-3583.

55. R. Díaz-Torres, S. Alvarez, Dalton Trans. 2011, 40, 10742-10750.

56. T.D. Newbound, M.R. Colsman, M.M. Miller, G.P. Wulfsburg, O.P. Anderson, S.H. Strauss. J. Am. Chem. Soc. 1989, 111, 3762-3764. 